\title{
Como mulheres e homens contribuem para a desigualdade da renda domiciliar per capita no Brasil *
}

\author{
Rodolfo Hoffmann **
}

\begin{abstract}
Resumo
O artigo analisa como os rendimentos do trabalho de mulheres e homens afetam a distribuição da renda domiciliar per capita (RDPC) no Brasil, destacando os rendimentos de esposas e maridos dos casais que incluem a pessoa de referência do domicílio. Para isso é relevante examinar a correlação entre as escolaridades de esposas e maridos, pois esses são condicionantes básicos dos respectivos rendimentos do trabalho. Também são analisadas as contribuições de aposentadorias e pensões, sempre distinguindo esposas, maridos, demais homens e demais mulheres de cada domicílio. São utilizados dados da Pesquisa Nacional por Amostra de Domicílios (PNAD) de 1992 a 2015. Verifica-se que a correlação entre escolaridades de maridos e esposas em 2015 é menor do que em 1995. Ao decompor a variação do índice de Gini da RDPC de 1995 a $2015(\Delta G=-0,086)$, verifica-se que as quatro parcelas relativas ao rendimento do trabalho e as quatro parcelas referentes a aposentadorias e pensões contribuem todas para a redução da desigualdade.
\end{abstract}

Palavras-chave: Distribuição da renda; Desigualdade; Índice de Gini; Escolaridade; Seletividade marital.

\begin{abstract}
How women and men contribute to income inequality in Brazil

This paper analyzes how the earnings of women and men affect the per capita household income (PCHI) distribution in Brazil, highlighting the individual earnings of the wife and husband of the couples, which include the household's reference person. For this it is relevant to analyze what happens with the correlation between the husband's and wife's schooling, since level of schooling is a basic determinant of their earnings. Income from pensions is also analyzed, distinguishing income received by the husband, the wife, other men and other women. Data from a National Annual Household Survey for the period 1992-2015 are used. The correlation between the husband's and wife's schooling in 2015 is lower than in 1995. Decomposing the reduction of the Gini index from 1995 to 2015 $(\Delta G=-0,086)$, it is verified that the four components related to earnings and the four components formed by pensions contributed to the reduction in inequality.
\end{abstract}

Keywords: Income distribution; Inequality; Gini index; Schooling; Assortative mating.

JEL D31, D33, J12, J16.

\section{Introdução}

O objetivo central do artigo é analisar como os rendimentos de homens e mulheres contribuem para a desigualdade da distribuição da renda domiciliar per capita (RDPC) no Brasil, de 1995 a 2015. É dada especial atenção aos rendimentos do marido e da esposa quando um dos membros do casal é pessoa de referência do domicílio.

\footnotetext{
*Artigo recebido em 4 de dezembro de 2017 e aprovado em 8 de junho de 2018.

** Professor Sênior da Escola Superior de Agricultura "Luiz de Queiroz" da Universidade de São Paulo (Esalq-USP), Piracicaba, SP, Brasil. E-mail: hoffmannr@usp.br.
} 
Preliminarmente, são lembrados os trabalhos que abordaram esse tema ao analisar a distribuição da renda no Brasil e, em seguida, é analisada a evolução da taxa de atividade de homens e mulheres e, dado que a escolaridade é um dos principais determinantes do rendimento obtido pelas pessoas no seu trabalho, examina-se, também, como cresceu a escolaridade de homens e mulheres e como variou a correlação entre escolaridades de maridos e esposas.

Após a análise da seletividade marital educacional, será utilizada a técnica de decomposição estática e dinâmica do índice de Gini para verificar como rendimentos de homens e mulheres, destacando maridos, esposas, demais homens e demais mulheres, contribuíram para a queda da desigualdade da distribuição da RDPC no Brasil de 1995 a 2015.

São utilizados os dados da Pesquisa Nacional por Amostra de Domicílios (PNAD), de 1992 a 2015. A pesquisa não foi feita em 1994 e nos anos em que houve Censos Demográficos (2000 e 2010). Como até 2003 a PNAD não incluía dados na área rural da antiga Região Norte, os dados dessa área foram excluídos das PNAD de 2004 em diante, para uniformizar a abrangência geográfica da amostra ao longo da série temporal. Assim, neste artigo, quando estiver sendo analisada uma série de dados anuais, "Brasil" significa o País sem a área rural da antiga Região Norte.

A elaboração deste artigo começou como tentativa de entender a afirmativa de Pereira e Santos (2017), baseada nos Censos Demográficos de 1970 a 2010, de que o grau de casamento seletivo (pareamento dos níveis de escolaridade) havia crescido de forma considerável no Brasil, pois isso contraria resultados de pesquisas anteriores, como Silva (2003) e Ribeiro e Silva (2009).

É importante ter em mente que a correlação entre escolaridades de marido e esposa não é uma maneira apropriada de captar a semelhança ou não de características socioeconômicas nos casamentos de um passado mais distante. Quando não havia perspectiva de participar no mercado de trabalho, era muito menor o incentivo para investir na escolaridade das mulheres. Mas a ausência de pareamento entre escolaridades não significa que não houvesse tendência de casamentos dentro do mesmo nível de status socioeconômico e até mesmo os casamentos combinados para aumentar o patrimônio familiar. Idealmente, seria necessário analisar como variou, ao longo dos anos, a correlação entre o status socioeconômico dos noivos.

\section{Trabalhos anteriores sobre o tema}

Hoffmann e Kageyama (1986) constataram que, no Brasil, entre 1970 e 1980 aumentou a desigualdade da distribuição da renda entre pessoas economicamente ativas, mas diminuiu a desigualdade da distribuição da renda familiar e mostram que naquela década o aumento do número de pessoas com rendimento por unidade familiar foi mais acentuado para as famílias pobres. O artigo ressalta o crescimento da proporção de mulheres na população economicamente ativa, de 20,9\% em 1970 para 27,4\% em 1980. 
Hoffmann e Leone (2004), usando dados da PNAD, examinaram como a participação das mulheres no mercado de trabalho afetou a distribuição da RDPC no Brasil, de 1981 a 2002. Nesse período, a razão de concentração do rendimento de mulheres (esposas ou não) permaneceu um pouco acima do índice de Gini, indicando que o rendimento das mulheres contribuiu, em cada ano, para tornar mais elevada a desigualdade da distribuição da RDPC.

Silva (2003) examina a seletividade marital educacional no Brasil utilizando dados da PNAD para 1981, 1990 e 1999. Verifica que a proporção de casais em que os cônjuges têm o mesmo nível educacional (casamentos homogâmicos) declinou de 56\%, em 1981, para 51\% em 1999, ressaltando que isso pode ser devido a mudanças nas distribuições de maridos e esposas. Por meio do ajuste de um modelo log-linear ele controla essas mudanças nas distribuições marginais e conclui que "as evidências apontam para a constância das restrições que governam a seletividade marital, a redução observada na homogamia bruta sendo explicável pelas mudanças nas distribuições de escolaridade dos cônjuges" (p. 377).

Ribeiro e Silva (2009) utilizam dados dos Censos Demográficos de 1960, 1980 e 2000 para um estudo profundo da seletividade marital no Brasil, considerando tanto a escolaridade como a cor das pessoas. Para evitar o efeito de segundos casamentos, restringem a análise a casais em que marido e esposa tinham entre 20 e 34 anos. Com base em tabelas nas quais classificam maridos e esposas em cinco níveis de escolaridade (0-3, 4-7, 8, 9-11 e 12 ou mais), mostram que a proporção de casamentos educacionalmente homogêneos diminuiu de 79,2\% em 1960 para 59,4\% em 1980 e 48,1\% em 2000. Também usam modelos log-lineares para controlar os efeitos das distribuições marginais. Uma das suas conclusões é que "casamentos entre pessoas com níveis educacionais distintos são cada vez mais comuns" (p. 46).

Pereira e Santos (2017) se inspiram em trabalhos de Greenwood et al. (2014 e 2016) sobre os Estados Unidos e analisam o efeito da seletividade nos casamentos sobre a distribuição da renda familiar no Brasil, utilizando dados dos Censos Demográficos de 1970 a 2010. Classificando maridos e esposas em quatro níveis educacionais (educação primária incompleta, primária, secundária e universidade), calculam o coeficiente de correlação de Kendall $(\tau)$ e mostram que ele aumentou substancialmente de $1970(\tau=0,12)$ para $2010(\tau=0,44)$ (com enorme aumento de 1970 a 2000 e ligeira redução de 2000 a 2010). Com base em simulações contrafactuais, mostram que se os casamentos fossem aleatórios, o índice de Gini teria diminuído mais (teria diminuído 0,044 em lugar dos 0,037 observados, com redução de 0,609 para 0,572). Os autores concluem que "os brasileiros estão se casando cada vez mais com parceiros que possuem características socioeconômicas semelhantes" e que "a distribuição de renda brasileira teria melhorado ainda mais, caso a tendência de casamentos seletivos não tivesse ocorrido". Eles notam que o efeito sobre a desigualdade depende de como o aumento da participação das mulheres no mercado de trabalho se distribui pelos estratos de renda, mas não incorporam isso nas conclusões.

Como trabalho anterior sobre casamentos seletivos no Brasil, Pereira e Santos (2017) mencionam apenas estudo de Neri (2005) que, utilizando dados dos Censos Demográficos de 1970 e 2000, apresenta tabelas de contingência classificando chefes e cônjuges em cinco níveis 
de escolaridade ( $0,1-3,4-7,8$-11 e 12 ou mais) e mostra que o percentual de casamentos dentro dos mesmos grupos educacionais diminuiu de 56,7\% em 1970 para 49,6\% em 2000. Pereira e Santos (2017) notam que esse resultado seria, à primeira vista, contraditório com os seus e observam, corretamente, que Neri não usou uma medida que controlasse os efeitos das mudanças nas distribuições marginais. Entretanto, calculando as medidas de seletividade usadas por Pereira e Santos para as tabelas de contingência $5 \times 5$ apresentadas por Neri para 1970 e 2000 e para as obtidas por Ribeiro e Silva para 1960, 1980 e 2000, obtive resultados muito diferentes dos de Pereira e Santos (2017) ${ }^{1}$. Note-se que Pereira e Santos (2017) nem mencionam o artigo de Ribeiro e Silva (2009).

Ribeiro e Machado (2018) $)^{2}$ utilizam dados da PNAD de 1992 a 2014 para analisar a mudança na desigualdade da distribuição da RDPC, medida pelo quadrado do coeficiente de variação, considerando sua decomposição conforme componentes da renda (rendimento do trabalho do marido, rendimentos do trabalho da esposa e outras rendas) ou conforme tipos de família (chefiadas por casais ou não). A amostra foi limitada aos casais heterossexuais em que ambos os cônjuges tinham entre 25 e 55 anos e outros tipos de família em que a pessoa de referência tinha entre 25 e 55 anos, excluindo " 177 domicílios cuja renda per capita era superior a vinte desvios-padrão da média do respectivo ano". Os autores concluem que "apesar do aumento da associação entre os rendimentos dos cônjuges, o efeito líquido das mudanças nos rendimentos das esposas durante o período analisado foi equalizador".

Hakak e Firpo $(2017)^{3}$ utilizam dados da PNAD de 1992, 1999, 2001, 2005, 2009 e 2014 referentes a casais nos quais a idade média de marido e esposa está entre 26 e 60 anos. Encontram evidência de que nos últimos 20 anos houve redução do pareamento da escolaridade dos cônjuges, mas aumento do pareamento em casais com educação superior. Por meio de simulações contrafactuais, os autores verificam que, mantido o pareamento de 1992, o índice de Gini em 2014 seria 1,35\% menor do que o observado, considerando apenas a amostra de casais utilizada.

\section{Evolução da taxa de atividade de mulheres e homens}

A taxa de atividade é a proporção de pessoas de determinada faixa de idade que participa do mercado de trabalho, isto é, faz parte da População Economicamente Ativa (PEA).

(1) Mesmo usando os dados da Tabela 1 de Pereira e Santos (2017) obtive resultados que não confirmam o intenso crescimento da seletividade indicado por sua Figura 2. Após padronização das distribuições marginais, verifiquei que o valor da medida $\delta$ usada por eles aumenta de 2,3 em 1970 para 2.4 em 2010 (e não de 1,1 para 2,3, como indica sua Figura 2).

(2) Somente depois de completar a primeira versão do presente artigo é que tomei conhecimento do trabalho de Ribeiro e Machado (2018). O primeiro autor gentilmente me enviou cópia do artigo na sua versão final para publicação.

(3) Trata-se de trabalho não publicado, indicado por um dos pareceristas de Economia e Sociedade. Ao interpretar seus resultados, Hakak e Firpo afirmam, repetidamente, que o retorno da educação tem decrescido, quando uma análise mais detalhada revela que essa taxa mostra clara tendência decrescente para pessoas com até 10 anos de estudo, mas que para escolaridade acima de 10 anos a taxa só decresceu em período mais recente. No conjunto dos setores não agrícolas e para pessoas com escolaridade acima de 10 anos, essa taxa de retorno foi crescente de 1992 a 2002, passando a decrescer apenas depois de 2002 (Hoffmann; Oliveira, 2014). 
Utilizando os microdados da PNAD, calculamos essa taxa para todas as pessoas de 10 anos ou mais de idade e considerando apenas aquelas com 20 anos ou mais de idade, conforme o sexo. A Figura 1 mostra como essas taxas evoluíram de 1992 a 2015. Para o conjunto de homens e mulheres (linha verde) observa-se ligeira redução da participação de 1992 a 2015, sem tendência definida. Para mulheres há tendência de crescimento de 1992 a 2005. Já para os homens há clara tendência decrescente no período analisado.

Figura 1

Taxa de atividade de pessoas (homens e mulheres) com 10 anos ou mais de idade ou apenas para as com 20 anos ou mais. Brasil, 1992 a 2015

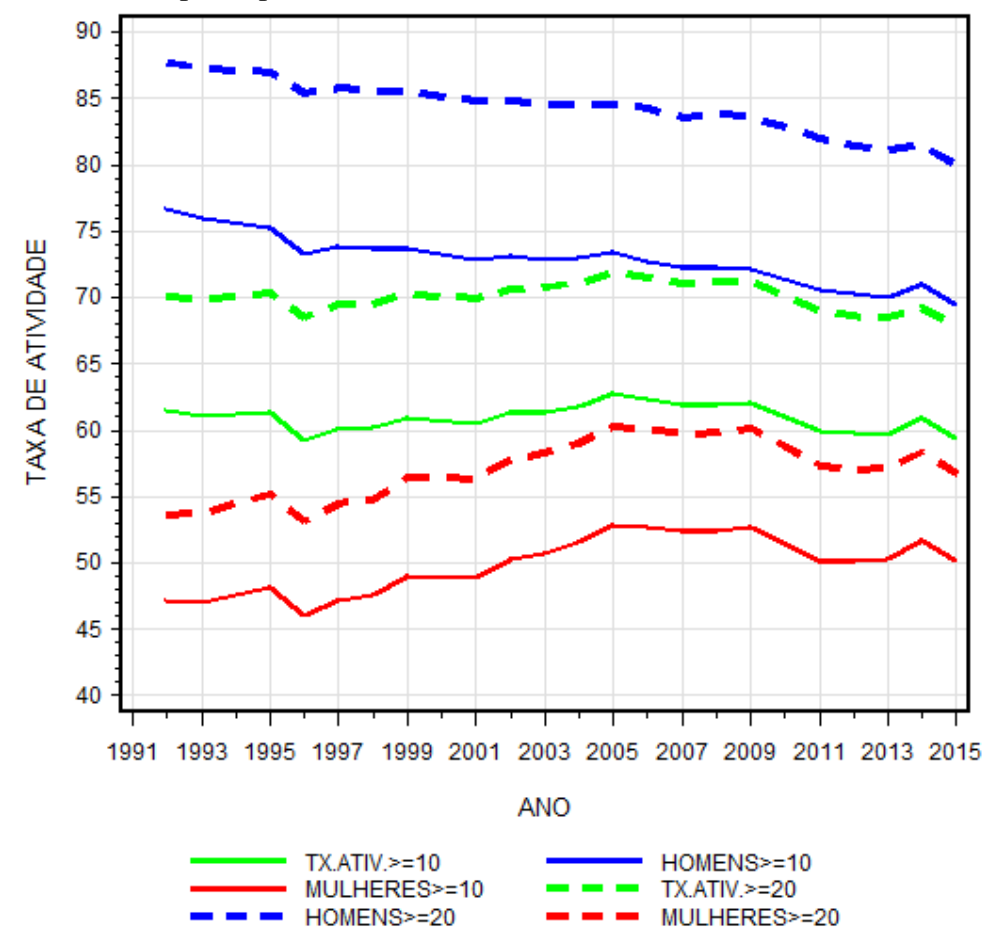

A Figura 2 permite verificar como a taxa de atividade variou em cada faixa de idade. Essa taxa foi calculada para faixas de idade com amplitude de 5 anos: 10 a menos de 15 anos, 15 a menos de 20 anos, ..., 75 a menos de 80 anos. Isso foi feito para mulheres e para homens, com os dados das PNADs de 1995, 2005 e 2015. Note-se que a linha da taxa de atividade das mulheres em 2015 fica, em geral, substancialmente acima da linha de 1995. Mas não se trata de um deslocamento de toda a linha para cima. A linha muda de forma. Nas duas primeiras faixas de idade a taxa de atividade das mulheres diminui (certamente em função de crescente escolarização) e o mesmo acontece na faixa de 70 a menos de 75 anos de idade (graças a mais aposentadorias e pensões). Esse tipo de mudança na taxa de atividade feminina por faixa de idade já vinha ocorrendo antes, como pode ser observado na Figura 2 de Hoffmann e Leone (2004), com dados desde 1981. 
Note-se, na Figura 2, que quase toda a mudança na taxa de atividade feminina de 1995 a 2015 ocorreu de 1995 a 2005.

Figura 2

Taxa de atividade de homens e de mulheres conforme faixas de idade, no Brasil, em 1995, 2005 e 2015



\section{O crescimento da escolaridade}

A escolaridade média tem crescido continuamente no Brasil, sendo que esse crescimento foi mais intenso para as mulheres do que para os homens, como mostra a Figura 3.

Na PNAD as pessoas são classificadas em 16 níveis de anos de estudo, de "sem instrução a menos de 1 ano" (que consideramos como escolaridade igual a zero) a "15 anos ou mais" (que admitimos que corresponde, em média, a 17 anos de escolaridade). Assim, a escolaridade atribuída a cada pessoa é um número inteiro de zero a 14 ou 17. Foram excluídas, obviamente, as pessoas com anos de estudo "não determinados".

Em 1992 a escolaridade média assim calculada, para pessoas de 20 anos ou mais de idade, ainda era ligeiramente maior para homens (5,29 anos) do que para mulheres $(5,27$ anos), mas em 2015 a escolaridade média das mulheres $(8,64)$ era substancialmente maior do que a dos homens $(8,22)$. 
Como mulheres e homens contribuem para a desigualdade da renda domiciliar per capita no Brasil

Figura 3

Escolaridade média das pessoas com 20 anos ou mais de idade. Brasil, 1992 a 2015

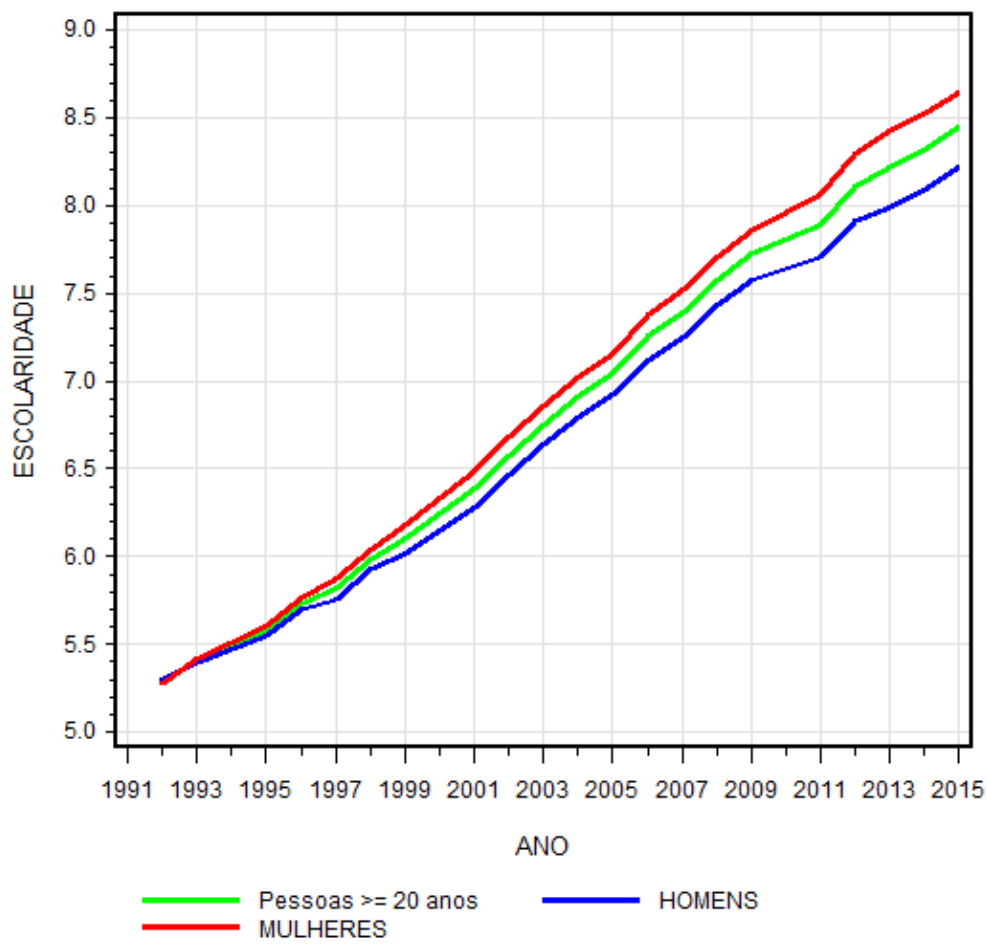

Nota-se, na Figura 3, que a escolaridade média em 2011 é ligeiramente baixa em relação à linha de tendência. Isso está associado a um número relativamente alto de pessoas com escolaridade igual a zero nesse ano. A porcentagem de pessoas com 20 anos ou mais de idade com escolaridade igual a zero mostra tendência claramente decrescente de 1992 a 2015. Em 2009 essa porcentagem é 11,30\% e em 2012 é 10,47\%, mas em 2011 atinge 13,35\%. Verifica-se que esse valor é estatisticamente discrepante na tendência linear decrescente de 1992 a 2015. É provável que na PNAD de 2011 tenha havido erro de registro da escolaridade de pessoas que não tinham completado o ensino fundamental. Com a mudança da duração do ensino fundamental de 8 para 9 anos, o IBGE ajustou a contagem dos anos de estudo a partir da PNAD de 2007 para possibilitar a comparação com as pesquisas anteriores. "Na contagem dos anos de estudo para o ensino fundamental com duração de 9 anos, a primeira série concluída com aprovação foi enquadrada em menos de 1 ano de estudo, a segunda série, em 1 ano de estudo, e assim, sucessivamente, até a nona série, classificada em 8 anos de estudo" IBGE (2008, p. 28). Pode ser que esse ajuste tenha levado, na PNAD de 2011, a rebaixar indevidamente a escolaridade de pessoas que não tinham completado o ensino fundamental de 8 anos. Note-se, entretanto, que esse erro não chega a alterar a tendência claramente crescente das escolaridades médias, como mostra a Figura 3. 
A Figura 4 mostra como a escolaridade média varia com a idade, nas PNADs de 1995, 2005 e 2015. Para isso calculamos, em cada ano, a escolaridade média para 12 faixas de idade (25 a menos de 30 anos, 30 a menos de $35, \ldots, 80$ a menos de 85 ). Não são consideradas faixas de idade mais baixa porque nelas haveria muitas pessoas ainda cursando escola. Com o passar dos anos, as curvas se deslocam para cima, mostrando o crescimento geral da escolaridade média. $\mathrm{O}$ fato de as linhas serem decrescentes mostra que as gerações mais novas são mais escolarizadas do que as gerações mais velhas. Para os mais jovens a escolaridade média das mulheres é maior do que a escolaridade média dos homens, mas ocorre o inverso para os mais idosos.

Figura 4

Escolaridade média por faixa de idade (20-24, 25-29, ..., 80-84), no Brasil (para população total, para homens e para mulheres), nas PNADs de 1995, 2005 e 2015

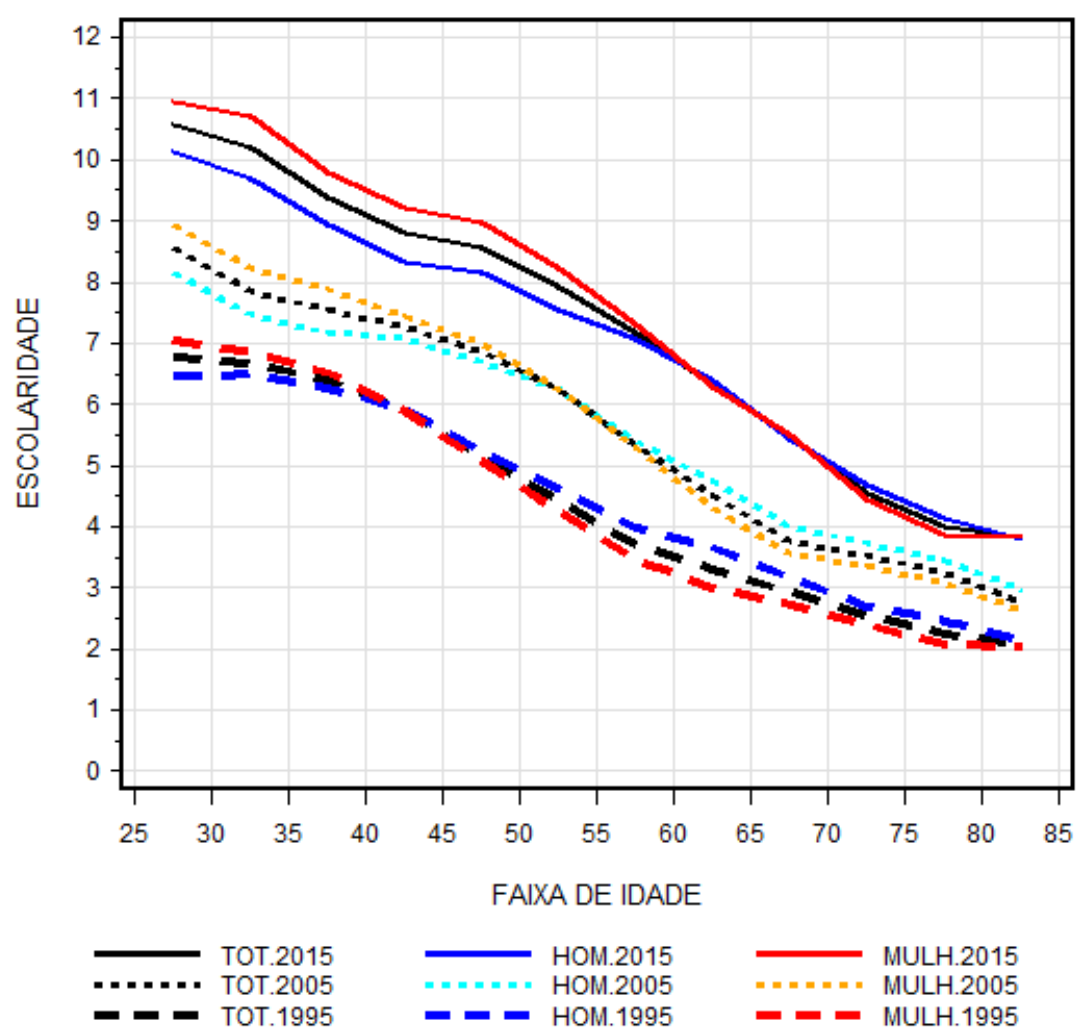

Como são utilizadas PNADs com defasagem de 10 anos, valores para a mesma coorte podem ser lidos na Figura 4 considerando um deslocamento de 10 anos no eixo das abscissas. Note-se, por exemplo, a semelhança nas ordenadas dos três conjuntos de linhas comparando a faixa de idade 50-55 na PNAD de 1995, a faixa 60-65 na PNAD de 2005 e a faixa 70-75 na PNAD de 2015. Por outro lado, Há um nítido crescimento da ordenada quando se compara a 
faixa de idade 35-40 da PNAD de 2005 com a faixa 25-30 da PNAD de 1995, pois nessa idade muitos ainda estão aumentando sua escolaridade.

Analisando dados dos Censos Demográficos de 1960 a 2000, Beltrão e Alves (2009) mostram o persistente crescimento da escolaridade média ${ }^{4}$. Considerando a escolaridade média das pessoas com 5 anos ou mais conforme o sexo, eles mostram que a "reversão do hiato de gênero no Brasil aconteceu na década de 1980”.

Quando se considera apenas a população economicamente ativa (PEA), em todo o período 1992-2015 a escolaridade média das mulheres permanece pelo menos 1,3 anos acima da escolaridade média dos homens, como mostra a Figura 5. Essa maior diferença nas escolaridades médias de homens e mulheres na PEA, em comparação com o que ocorre na população que inclui pessoas fora da PEA, se deve ao fato de a taxa de atividade aumentar mais fortemente com a escolaridade para as mulheres do que para os homens ${ }^{5}$.

Figura 5

Escolaridade média da PEA, no Brasil, de 1995 a 2015

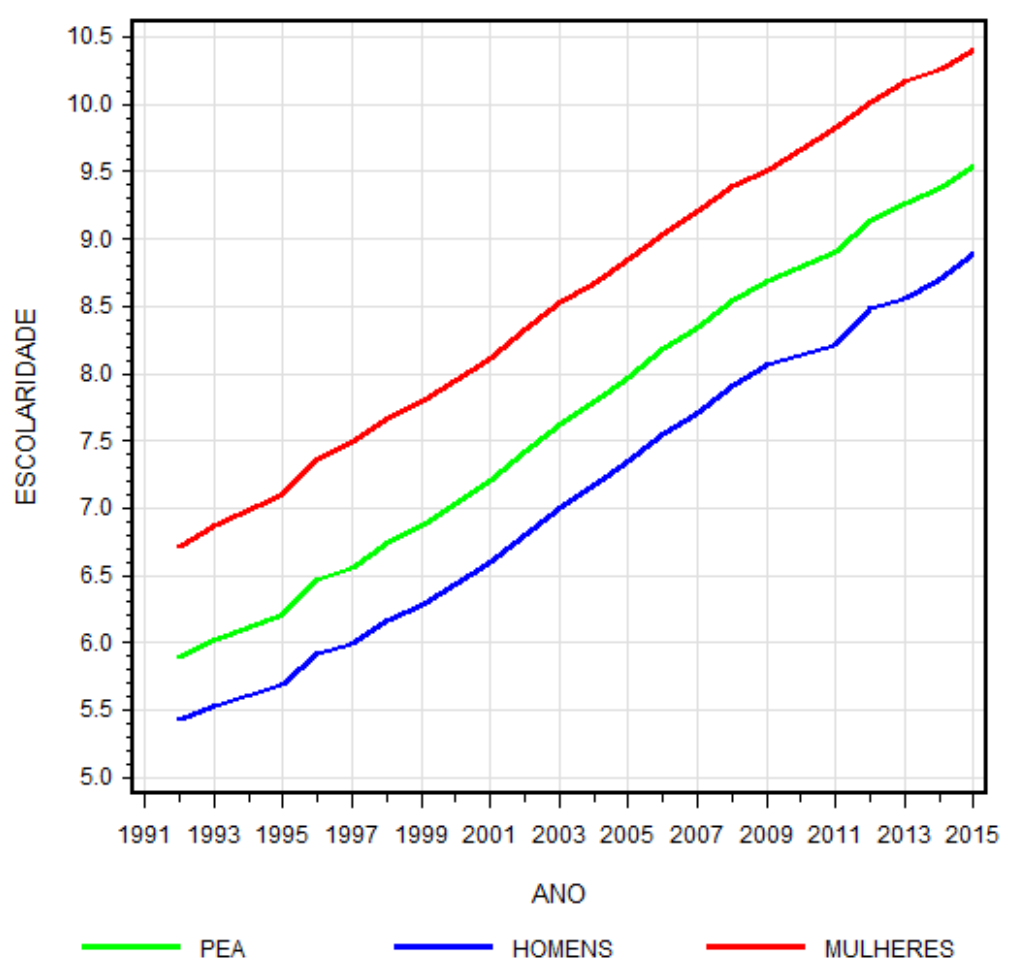

(4) Certamente há erro na Figura 3 de Pereira e Santos (2017, p. 365), ao indicar estabilidade ou decréscimo nas escolaridades médias de homens e mulheres no Brasil de 1970 a 1980. O erro está na fonte utilizada, o trabalho de Barro e Lee (2013).

(5) Com dados da PNAD de 2015 estimamos que, para pessoas com 20 anos ou mais de idade, cada ano a mais de escolaridade está associado, em média, a um aumento de 1,9 pontos percentuais na taxa de atividade de homens e um aumento de 3,5 pontos percentuais na taxa de atividade de mulheres. 
Rodolfo Hoffmann

\section{Os casais, as escolaridades dos cônjuges e seus rendimentos}

Uma vez constatados e avaliados o aumento da participação das mulheres no mercado de trabalho e o crescimento mais rápido da escolaridade das mulheres, nesta seção vamos examinar a correlação entre escolaridades de maridos e esposas, tendo em vista, posteriormente, verificar como rendimentos de maridos e esposas contribuem para a desigualdade da renda domiciliar per capita (RDPC) no Brasil.

A grande maioria dos domicílios é formada por uma única família, mas há domicílios com duas ou mais famílias. Em geral, os analistas da distribuição da renda no Brasil têm optado por utilizar a RDPC, e não a renda familiar per capita, tendo em vista que uma família secundária no domicílio geralmente é economicamente dependente da família principal. Para examinar a contribuição dos rendimentos de marido e esposas para a distribuição da RDPC, vamos considerar apenas os casais em famílias de referência dos domicílios, isto é, famílias que incluem a pessoa de referência do domicílio. Na PNAD de 2015, 95,7\% das famílias com declaração de rendimento familiar eram famílias de referência do domicílio, 4,0\% eram famílias secundárias e apenas $0,3 \%$ estavam em domicílios com três ou mais famílias (com máximo de 5 famílias por domicílio).

Dado que o objetivo é analisar a distribuição da RDPC, no que se segue consideramos apenas domicílios particulares permanentes com declaração do rendimento domiciliar. Tendo em vista as distorções que a inflação muito elevada causa nas informações sobre o rendimento, limitaremos a análise ao período 1995-2015.

Considerando o sexo da pessoa de referência do domicílio e o fato de ela ter ou não cônjuge, podemos distinguir 5 tipos de domicílio:

a) Casal heterossexual; a participação desse tipo no total caiu de 73,1\% em 1995 para $62,7 \%$ em 2015.

b) Pessoa de referência masculina sem cônjuge; a participação desse tipo no total subiu de 7,2\% em 1995 para 11,3\% em 2015.

c) Pessoa de referência feminina sem cônjuge, cuja participação cresceu de $19,7 \%$ em 1995 para 25,8\% em 2015.

d) Casal homossexual feminino, sem registro antes de 2007 e representando $0,11 \%$ do total em 2015.

e) Casal homossexual masculino, sem registro antes de 2007 e correspondendo a $0,07 \%$ do total em 2015.

Em números redondos, houve uma redução de 10 pontos percentuais na participação de domicílios nos quais a pessoa de referência forma um casal, um aumento de 4 pontos percentuais na participação de domicílios cuja pessoa de referência é um homem sem cônjuge e um aumento de 6 pontos percentuais na porcentagem de domicílios cuja pessoa de referência é uma mulher sem cônjuge. 
Ocorreram várias outras mudanças na composição dos domicílios de 1995 a 2015, quando o número de domicílios cresceu de 38,1 para 65,4 milhões. O número médio de pessoas por domicílio diminuiu de 3,87 para 2,98. A proporção de domicílios com uma única pessoa aumentou de $8,6 \%$ para $15,4 \%$ e a proporção dos com 6 ou mais pessoas diminuiu de $16,3 \%$ para $5,1 \%$.

Vamos denominar de "marido" e "esposa" os homens e mulheres, respectivamente, que formam os casais heterossexuais nos quais um dos cônjuges é pessoa de referência do domicílio. Todas as outras pessoas de 10 anos ou mais de idade são classificadas como "demais homens" e "demais mulheres".

A Figura 6 mostra a evolução da escolaridade média de esposas e maridos. Como esperado, o padrão é semelhante ao observado na Figura 3, que mostra a evolução da escolaridade média de mulheres e homens com 20 anos ou mais de idade. Comparando as Figuras 3 e 6, constata-se que a diferença de escolaridade a favor das esposas, em comparação com os maridos, é maior do que a diferença a favor das mulheres, em comparação com homens de 20 anos ou mais de idade.

Figura 6

Escolaridades médias de maridos e esposas, no Brasil, de 1995 a 2015

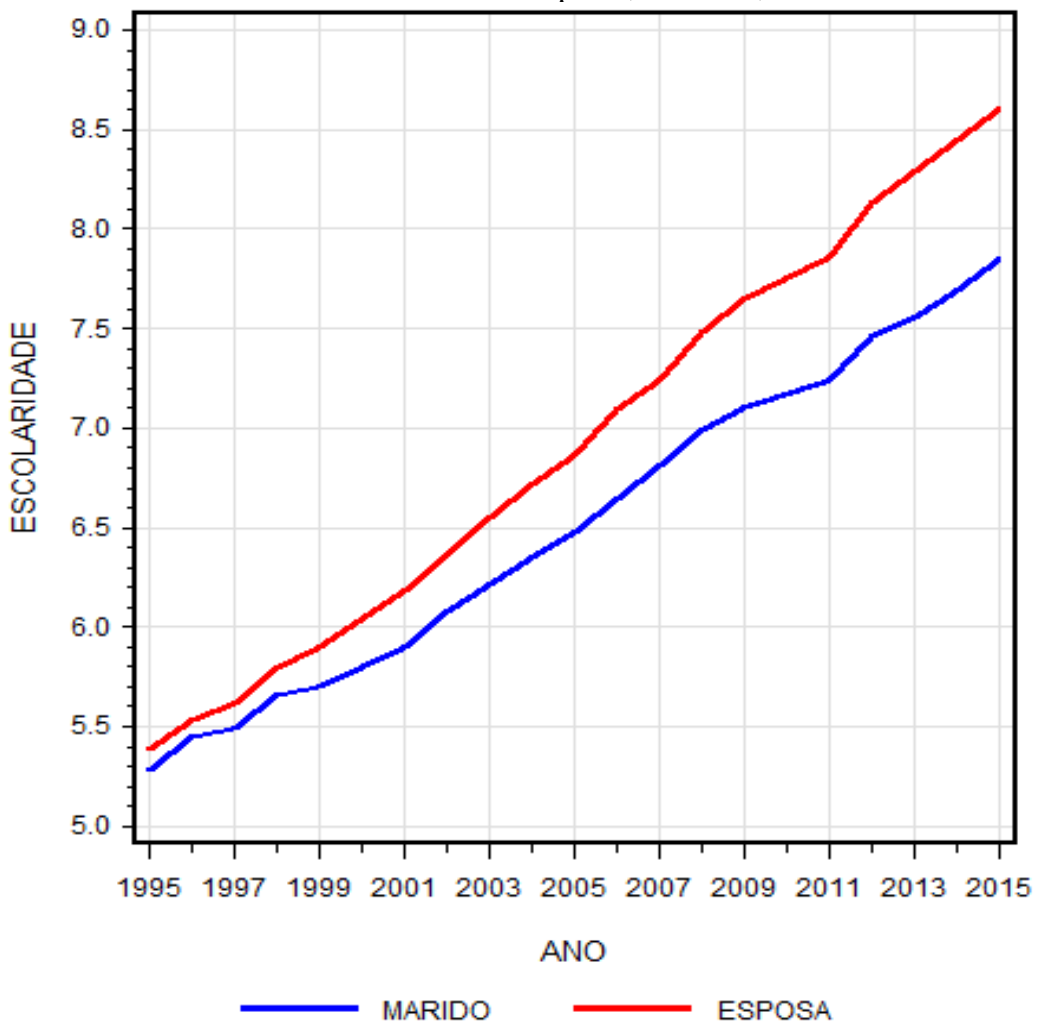


O crescimento da participação de mulheres no mercado de trabalho aumenta o rendimento das famílias e dos domicílios onde isso ocorre e, obviamente, afeta a distribuição da RDPC.

Com base nos dados das PNADs de 1995 a 2015 não se constata tendência de crescimento da correlação entre escolaridades de marido e esposa no Brasil. Pelo contrário, a Figura 7 mostra a tendência decrescente de várias medidas de correlação, considerando os 16 níveis de escolaridade definidos anteriormente (ao apresentar a Figura 3). Além do coeficiente de correlação de Pearson com ou sem ponderação pelo fator de expansão da amostra da PNAD, são utilizadas duas medidas de correlação ordinal, a de Spearman e a de Kendall ( $\tau$, com correção para empates), ambas sem ponderação. Observa-se uma queda mais acentuada das medidas de correlação de 2006 a 2007, que pode estar associada a maior "ruído" nos dados devido ao ensino fundamental ter passado de 8 para 9 anos.

Figura 7

Correlação entre escolaridades do marido e da esposa, no Brasil, de 1995 a 2015

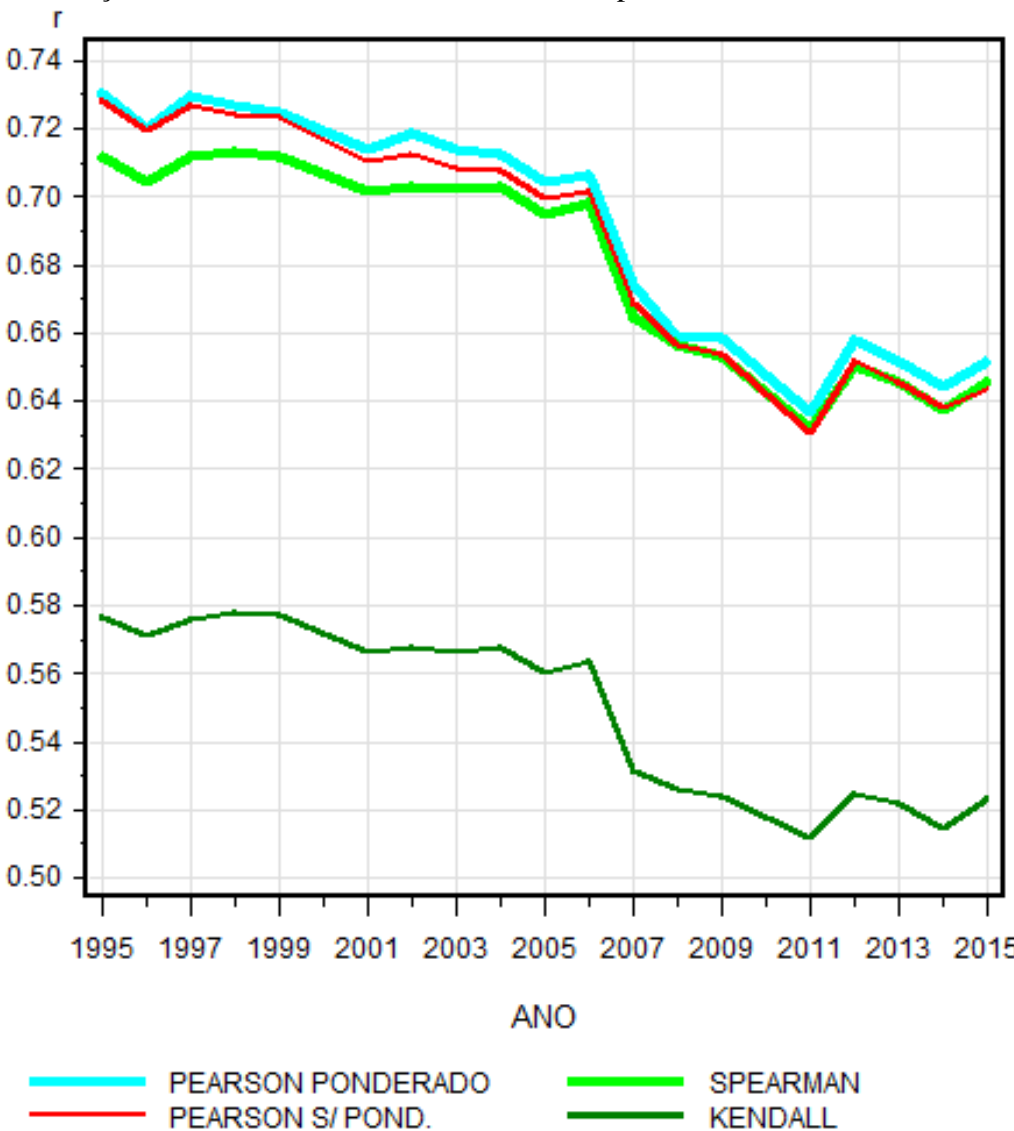


Análises do fenômeno nos Estados Unidos mostram que houve períodos nos quais ocorreu, simultaneamente, mais pareamento em determinado nível educacional e menos pareamento em outro nível educacional ${ }^{6}$. Tendo em vista essa possibilidade, calculamos o valor do coeficiente de associação $\phi$ e a odds ratio $(\alpha)$ para tabelas $2 \times 2$ considerando três diferentes divisões binárias no nível de escolaridade de esposas e maridos: escolaridade até 4 anos versus escolaridade maior do que 4; até $1^{\circ}$ grau completo versus escolaridade maior que 8 anos e até $2^{\circ}$ grau completo versus mais de 11 anos de escolaridade. Para as seis medidas ocorre redução do grau de associação das escolaridades de esposas e maridos, no Brasil, de 1995 a 2015, como mostram os Figuras 8 e 9. Para uma tabela $2 \times 2$ com frequências $n_{11}, n_{12}, n_{21}$ e $n_{22}$ e frequências marginais $n_{1 \cdot}=n_{11}+n_{12}, n_{2 \cdot}=n_{21}+n_{22}, n_{\cdot 1}=n_{11}+n_{21}$ e $n_{\cdot 2}=n_{12}+$ $n_{22}$, a medida de associação $\phi$ é definida como

$$
\phi=\frac{n_{11} n_{22}-n_{12} n_{21}}{\sqrt{n_{1} \cdot n_{2} \cdot n \cdot 1 \cdot n_{\cdot 2}}}
$$

e a odds ratio $(\alpha)$ é

$$
\alpha=\frac{n_{11} n_{22}}{n_{12} n_{21}}
$$

Figura 8

Coeficiente $\phi$ de tabelas $2 \times 2$ de nível de escolaridade do marido e da esposa, no Brasil, de 1995 a 2015

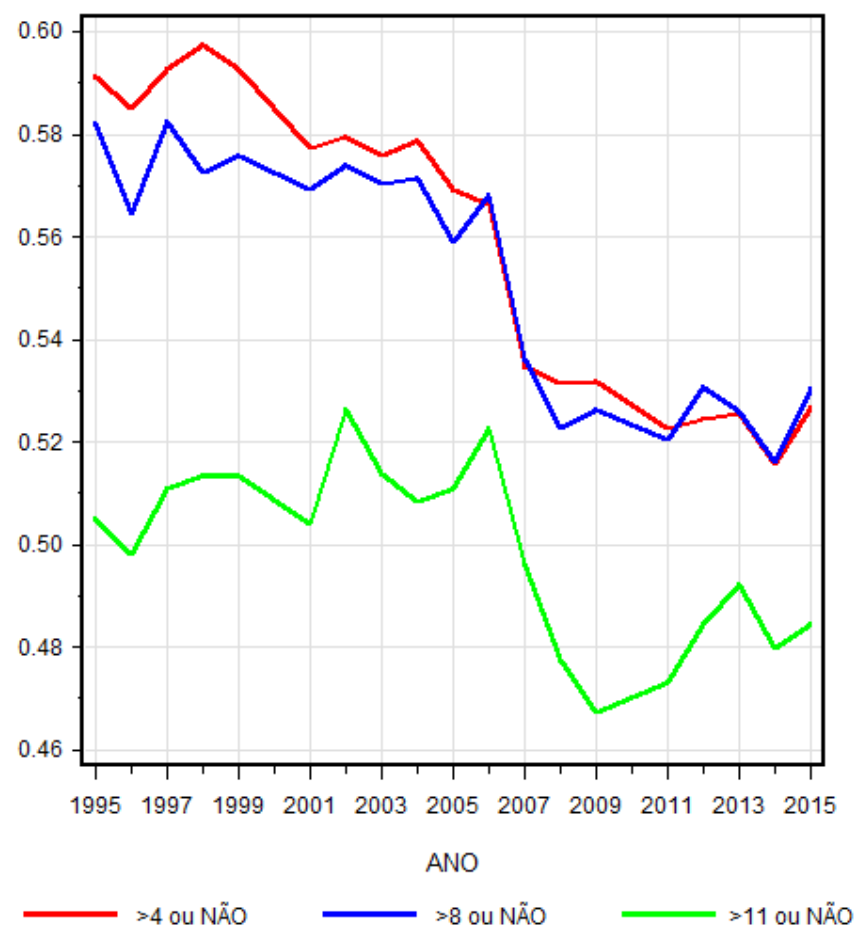

(6) Ver Schwartz e Mare (2005) e Eika, Mogstad e Zafar (2017). 
Figura 9

A odds ratio $(\alpha)$ de tabelas $2 \times 2$ de nível de escolaridade do marido e da esposa, no Brasil, 1995-2015



A seguir vamos analisar, nos dados da PNAD de 2015, como a associação entre as escolaridades de maridos e de esposas varia com a idade. Para isso vamos considerar faixas de idade do marido com amplitude de 5 anos: 25 a menos de 30 anos, 30 a menos de 35 anos, ..., 80 a menos de 85 anos. Dentro de cada faixa de idade calculamos o coeficiente de correlação de Pearson entre as duas escolaridades e também o coeficiente $\phi$ para tabelas $2 \times 2$ obtidas classificando maridos e esposas em duas categorias, conforme sua escolaridade supere ou não 11 anos. Os resultados estão na Figura 10. Observa-se uma mudança de padrão de variação ao atingir a faixa de 45 a menos de 50 anos de idade. Para os mais jovens o coeficiente $\phi$ é mais elevado, indicando que nessas novas gerações há maior pareamento das escolaridades, o que certamente é favorecido pelo prolongamento da escolarização e a redução da segregação por sexo nos cursos universitários. A Figura 11 mostra o extraordinário crescimento da proporção de maridos e esposas com escolaridade superior a 11 anos à medida que passamos para faixas de idade mais baixa do marido. As porcentagens mais baixas para a faixa de 25 a menos de 30 anos de idade tem explicação específica: nessa faixa de idade muitos ainda não completaram sua escolarização. No futuro, quando gerações com maior proporção de pessoas com escolaridade universitária ocuparem também os andares superiores da pirâmide etária da população do País, deverá crescer a correlação entre escolaridades de maridos e esposas. 
Figura 10

Correlação de Pearson entre as escolaridades do marido e da esposa e coeficiente $\phi$ de tabela $2 \times 2$ com dicotomia para escolaridade maior do que 11 ou não, conforme faixas de idade do marido, no Brasil, em 2015

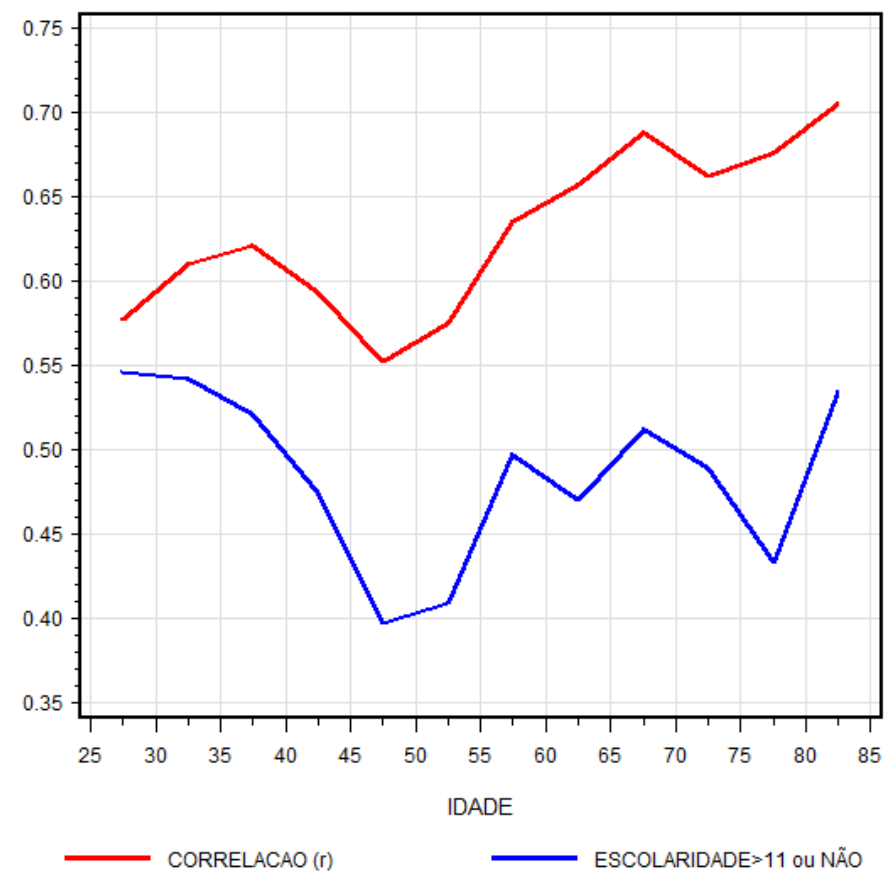

Figura 11

Porcentagem de maridos e de esposas com escolaridade superior a 11 anos, conforme faixas de idade do marido, no Brasil, em 2015

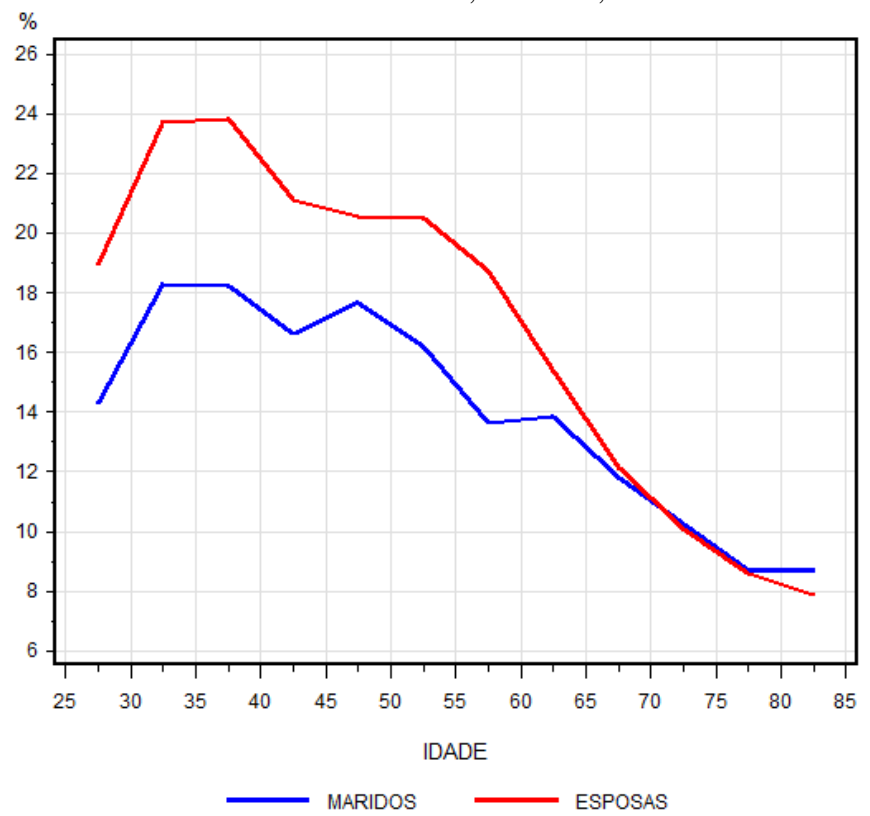


Já mencionamos que Pereira e Santos (2017) afirmam, com base nos Censos Demográficos de 1970 a 2010, que o grau de casamento seletivo (pareamento dos níveis de escolaridade) cresceu de forma considerável no Brasil. Os resultados apresentados aqui não confirmam tal afirmativa. Um problema do trabalho de Pereira e Santos (2017) é sua classificação em quatro níveis educacionais denominados "educação primária incompleta, primária, secundária e universidade". $\mathrm{Na}$ "educação primária incompleta" foram incluídas pessoas que não completaram o que hoje é denominado ensino fundamental, isto é, pessoas com escolaridade (como computada pelo IBGE) inferior a 8 anos. Observa-se, na tabela 1 do trabalho, que a primeira célula da tabela de contingência $4 \times 4$ inclui $85 \%$ dos casais em 1970 , tornando difícil captar adequadamente a seletividade educacional. Teria sido mais apropriado se esses autores tivessem, a exemplo de Ribeiro e Silva (2009) e Neri (2005), adotado uma classificação que discriminasse pessoas com até três anos de estudo e aquelas com 4 a 7 anos de estudo, tendo em vista que, para algumas gerações consideradas no Censo de 1970, ter o diploma de Grupo Escolar (4 anos de escolaridade) já era uma conquista importante. Uma pessoa que tivesse 50 anos de idade em 1970, por exemplo, provavelmente tinha completado sua escolarização antes de 1940.

Embora a correlação entre escolaridades de maridos e esposas tenha mostrado, em geral, tendência decrescente no período analisado, o mesmo não ocorreu com a correlação entre os rendimentos do trabalho de maridos e esposas. Tendo em vista a análise do efeito desses rendimentos sobre a distribuição do RDPC, que será desenvolvida na próxima seção, vamos considerar os valores per capita desses rendimentos, dividindo o rendimento do trabalho da pessoa ocupada pelo número de pessoas do domicílio correspondente (exclusive pensionistas, empregados domésticos e parentes de empregados domésticos). Os valores per capita dos rendimentos de maridos e esposas são indicados por $x_{1}$ e $x_{2}$, respectivamente.

Figura 12

Evolução dos coeficientes de correlação de Pearson (ponderado), de Spearman e de Kendall (ambos sem ponderação) entre os valores per capita do rendimento do trabalho de maridos e de esposas, no Brasil, de 1995 a 2015

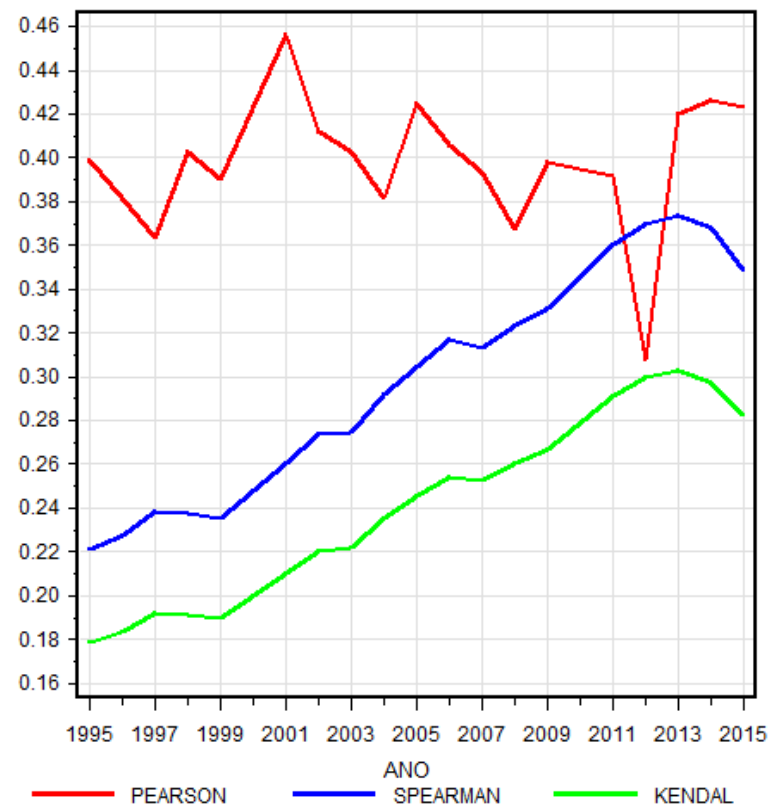


A Figura 12 mostra como evoluíram três medidas de correlação entre $x_{1}$ e $x_{2}$ : o coeficiente de correlação de Pearson (calculado com ponderação), e os coeficientes de correlação de Spearman e de Kendall (esses dois obtidos com os dados da amostra, sem ponderação). O coeficiente de correlação de Pearson oscila bastante de ano para ano, por ser altamente sensível às rendas muito altas, mas não apresenta tendência crescente ou decrescente. Por outro lado, os coeficientes de correlação de Spearman e de Kendall mostram clara tendência crescente de 1995 a 2013 e pequena queda de 2013 a 2015.

Ribeiro e Machado (2018) encontraram clara tendência crescente para o coeficiente de correlação de Pearson entre valores per capita dos rendimentos de maridos e esposas de 1992 a 2014 (ver sua Figura 2). Cabe ressaltar que essa tendência de crescimento do coeficiente fica mais fraca se forem excluídos os valores excepcionalmente baixo e alto observados em $1992 \mathrm{e}$ 2014, respectivamente. Considerando os dados da PNAD sobre casais heterossexuais analisados aqui, de 1995 a 2015, limitando a idade dos cônjuges ao intervalo de 25 a 55 anos e eliminando os domicílios com RDPC cujo desvio em relação à média do ano corresponde a um resíduo estudentizado externamente superior a 16, também constatamos uma tendência levemente crescente no coeficiente de correlação de Pearson entre $x_{1}$ e $x_{2}$. Essa depuração ${ }^{7}$ dos dados é semelhante à realizada por Ribeiro e Machado (2018), ficando claro que ela é essencial para que se constate tendência crescente no coeficiente de correlação de Pearson. A depuração não tem efeito relevante no comportamento das correlações de Spearman e de Kendall.

Quando a análise é limitada aos casais nos quais os dois cônjuges têm rendimento do trabalho ( $x_{1}$ e $x_{2}$ positivos), verifica-se que os coeficientes de correlação de Spearman e de Kendall mostram tendência ligeiramente decrescente de 1995 a 2015. Conclui-se, portanto, que o crescimento da correlação entre $x_{1}$ e $x_{2}$ para todos os casais se deve às mudanças na participação dos cônjuges no mercado de trabalho.

\section{Análise da contribuição dos rendimentos de esposas e maridos para a desigualdade da RDPC por meio da decomposição do índice de Gini}

A decomposição do índice de Gini conforme parcelas do RDPC foi utilizada por Hoffmann e Leone (2004) para analisar como rendimentos de mulheres e de homens contribuíram para a desigualdade, no Brasil, de 1981 a 2002. Nesse trabalho a RDPC foi dividida em quatro parcelas: rendimento do trabalho de homens, rendimento do trabalho de mulheres, aposentadorias e pensões e demais rendimentos.

(7) A depuração das rendas elevadas implicou na exclusão de 174 das 831.073 observações da amostra de domicílios chefiados por casais heterossexuais com 25 a 55 anos de idade. Em cada ano são excluídos de 7 a 13 domicílios. Em cerca de 80\% desses casos a renda predominante é a do marido. Como geralmente a renda muito elevada de um dos cônjuges não está associada com renda tão elevada do outro, e o coeficiente de correlação de Pearson é bastante sensível ao comportamento de valores mais afastados da média, a exclusão das rendas elevadas aumenta o valor e suaviza o comportamento desse coeficiente. 
Nesta seção a metodologia de decomposição dinâmica do índice de Gini será utilizada para avaliar como rendimentos recebidos por maridos, esposas, demais homens e demais mulheres de cada domicílio contribuíram para a variação do índice de Gini da RDPC no Brasil de 1995 a 2015. Para isso, a seguir é feita uma apresentação dessa metodologia.

Seja $x_{i}$ a RDPC da $i$-ésima pessoa em uma população de $n$ pessoas $(i=1, \ldots, n)$. Admite-se que essa renda seja formada por $k$ parcelas $x_{h i}, \operatorname{com} h=1, \ldots, k$, de maneira que

$$
x_{i}=\sum_{h=1}^{k} x_{h i}
$$

Os valores médios da RDPC e das suas parcelas são indicados por $\mu$ e $\mu_{h}(h=1, \ldots, k)$.

Admitindo que as pessoas estejam ordenadas de maneira que

$$
x_{1} \leq x_{2} \leq \cdots \leq x_{n},
$$

o índice de Gini pode ser definido como

$$
G=\frac{2}{n \mu} \operatorname{cov}\left(i, x_{i}\right)
$$

e a razão de concentração de cada parcela é

$$
C_{h}=\frac{2}{n \mu_{h}} \operatorname{cov}\left(i, x_{h i}\right)
$$

Ressalte-se que $i$ é a posição de ordem de $x_{i}$, e não, necessariamente, da parcela $x_{h i}$.

Sabe-se que o índice de Gini é uma média ponderada das razões de concentração

$$
G=\sum_{h=1}^{k} \varphi_{h} C_{h}
$$

onde $\varphi_{h}$ é a participação de $h$-ésima parcela na renda total da população, isto é,

$$
\varphi_{h}=\frac{\mu_{h}}{\mu}
$$

Seja $i_{h}$ a posição de ordem dos valores da $h$-ésima parcela $\left(x_{h}\right)$ quando eles são ordenados de maneira que

$$
x_{h 1} \leq x_{h 2} \leq \cdots \leq x_{h n}
$$

Os valores da parcela assim ordenados passam a ser indicados por $x_{h i_{h}}$. Então, analogamente a (3), o índice de Gini da $h$-ésima parcela pode ser definido como

$$
G_{h}=\frac{2}{n \mu_{h}} \operatorname{cov}\left(i_{h}, x_{h i_{h}}\right)
$$

De acordo com a Metodologia de Gini apresentada por Yitzhaki e Schechtman (2012), a razão

$$
R_{h}=\frac{C_{h}}{G_{h}}=\frac{\operatorname{cov}\left(i, x_{h i}\right)}{\operatorname{cov}\left(i_{h}, x_{h i_{h}}\right)}
$$

é a correlação de Gini de $x_{h}$ em relação a $x$. Esse tipo de correlação foi utilizado e discutido por Fei, Ranis e Kuo (1979) e Pyatt, Chen e Fei (1980). 
De (5) e (8) segue-se que

$$
G=\sum_{h=1}^{k} \varphi_{h} R_{h} G_{h}
$$

Sendo a renda $x$ dividida em $k$ parcelas, essa expressão mostra como o índice de Gini da distribuição de $x$ depende da participação de cada parcela na renda global $\left(\varphi_{h}\right)$, da correlação de Gini $\left(R_{h}\right)$ da parcela em relação a $x$ e do índice de Gini da distribuição da parcela $\left(G_{h}\right)$. Para ilustrar a interpretação da correlação $R_{h}$, vamos admitir que $x_{h}$ seja o valor per capita do rendimento do trabalho de esposas e que estamos analisando o efeito dessa parcela sobre a desigualdade da distribuição da RDPC. A expressão (9) mostra que, mesmo fixando a participação $\left(\varphi_{h}\right)$ e a desigualdade $\left(G_{h}\right)$ dessa parcela, seu efeito sobre a desigualdade final ainda depende de como o rendimento das esposas está associado à RDPC. Se o rendimento das esposas estiver concentrado nos domicílios mais pobres, $R_{h}$ será negativo e essa parcela irá contribuir para reduzir a desigualdade. Se, no outro extremo, o rendimento das esposas estiver concentrado a favor dos domicílios ricos $\left(R_{h} G_{h}=C_{h}>G\right)$, essa parcela irá contribuir para aumentar a desigualdade ${ }^{8}$.

Vamos admitir que seja conhecida a decomposição dinâmica do índice de Gini baseada em (5), quando se analisa a variação da desigualdade entre dois pontos no tempo, indicados por 1 e 2 (ver Hoffmann, 2006, ou Hoffmann, 2013):

$$
\Delta G=G_{2}-G_{1}=\sum_{h=1}^{k}\left[\left(\bar{C}_{h}-\bar{G}\right) \Delta \varphi_{h}+\bar{\varphi}_{h} \Delta C_{h}\right]
$$

onde o traço sobre a variável indica o valor da média aritmética dos seus valores nos momentos 1 e 2 . A primeira parcela dentro dos colchetes, no $2^{\circ}$ membro, é o efeito composição da parcela e a segunda parcela é o efeito concentração. Acrescentando a decomposição de

$$
\Delta C_{h}=\Delta\left(R_{h} G_{h}\right)=\bar{G}_{h} \Delta R_{h}+\bar{R}_{h} \Delta G_{h}
$$

obtemos

$$
\Delta G=\sum_{h=1}^{k}\left[\left(\bar{C}_{h}-\bar{G}\right) \Delta \varphi_{h}+\bar{\varphi}_{h} \bar{G}_{h} \Delta R_{h}+\bar{\varphi}_{h} \bar{R}_{h} \Delta G_{h}\right]
$$

Assim, a mudança no índice de Gini é decomposta em três efeitos:

a) o efeito composição, associado com mudanças $\left(\Delta \varphi_{h}\right)$ nas participações das parcelas na renda total;

b) o efeito correlação, devido às alterações $\left(\Delta R_{h}\right)$ nas correlações de Gini das parcelas com a renda final $x$;

c) o efeito desigualdade, decorrente das mudanças $\left(\Delta G_{h}\right)$ nos índices de Gini das parcelas.

A PNAD permite separar, para cada pessoa de 10 anos ou mais com algum rendimento, rendimentos do trabalho, aposentadorias e pensões, rendimento de aluguéis, doações de outros

(8) No Apêndice A é apresentado um exemplo numérico simples em que a distribuição de uma parcela é bastante desigual, contribuindo para reduzir ou para aumentar a desigualdade, dependendo da sua associação com a renda final ser mais fraca ou mais forte, respectivamente. 
Rodolfo Hoffmann

domicílios e o valor da última pergunta do questionário sobre rendimentos, que inclui juros, dividendos, valores recebidos de programas sociais (como o Bolsa Família) e outros rendimentos. Nos rendimentos do trabalho são incluídas remunerações em dinheiro ou em espécie recebidas pelo exercício de qualquer atividade como empregado, conta própria ou empregador.

Para facilitar a exposição, pessoas de 10 anos ou mais com rendimento serão denominadas de homens e mulheres.

Vamos considerar a divisão da RDPC nas 11 parcelas descritas a seguir.

1. Rendimento do trabalho do marido.

2. Rendimento do trabalho da esposa.

3. Rendimento do trabalho dos demais homens.

4. Rendimento do trabalho das demais mulheres.

5. Aposentadorias ou pensões do marido.

6. Aposentadorias ou pensões da esposa.

7. Aposentadorias ou pensões dos demais homens.

8. Aposentadorias e pensões das demais mulheres.

9. Total de doações recebidas pelas pessoas do domicílio.

10. Total de aluguéis recebidos pelas pessoas do domicílio.

11. Total de juros, dividendos e outros rendimentos.

Para todas essas 11 parcelas, o total em cada domicílio é dividido pelo número de pessoas do domicílio. Tanto no cálculo da renda domiciliar como na determinação do número de pessoas do domicílio, são excluídas as pessoas cuja condição no domicílio é pensionista, empregado doméstico ou parente de empregado doméstico.

Tendo em vista o objetivo deste trabalho, aqui será destacado o comportamento das 8 primeiras parcelas, referentes ao rendimento de atividade e a aposentadorias e pensões de homens e mulheres. Em 2015 essas 8 parcelas totalizavam 96,5\% da renda total declarada. O papel relevante da última parcela na redução da desigualdade, em função do crescimento dos benefícios distribuídos pelo Programa Bolsa Família e como Benefício de Prestação Continuada (BPC), é discutido em outros trabalhos (ver Hoffmann, 2017, e Jesus; Hoffmann, 2015).

A Figura 13 mostra, para quatro medidas, a redução da desigualdade da distribuição da RDPC no Brasil de 1995 a 2015, especialmente de 2001 a 2014. O índice de Gini passa de 0,599 em 1995 para 0,513 em 2015, com variação $\Delta G=-0,086$.

A Figura 14 mostra como variou, no período, a participação das 8 primeiras parcelas. A redução da participação do rendimento de marido (de 0,469 para 0,348 ) contrasta com a ligeira tendência crescente das outras 7 parcelas. 
Como mulheres e homens contribuem para a desigualdade da renda domiciliar per capita no Brasil

Figura 13

Quatro medidas de desigualdade da distribuição da RDPC no Brasil, 1995-2015

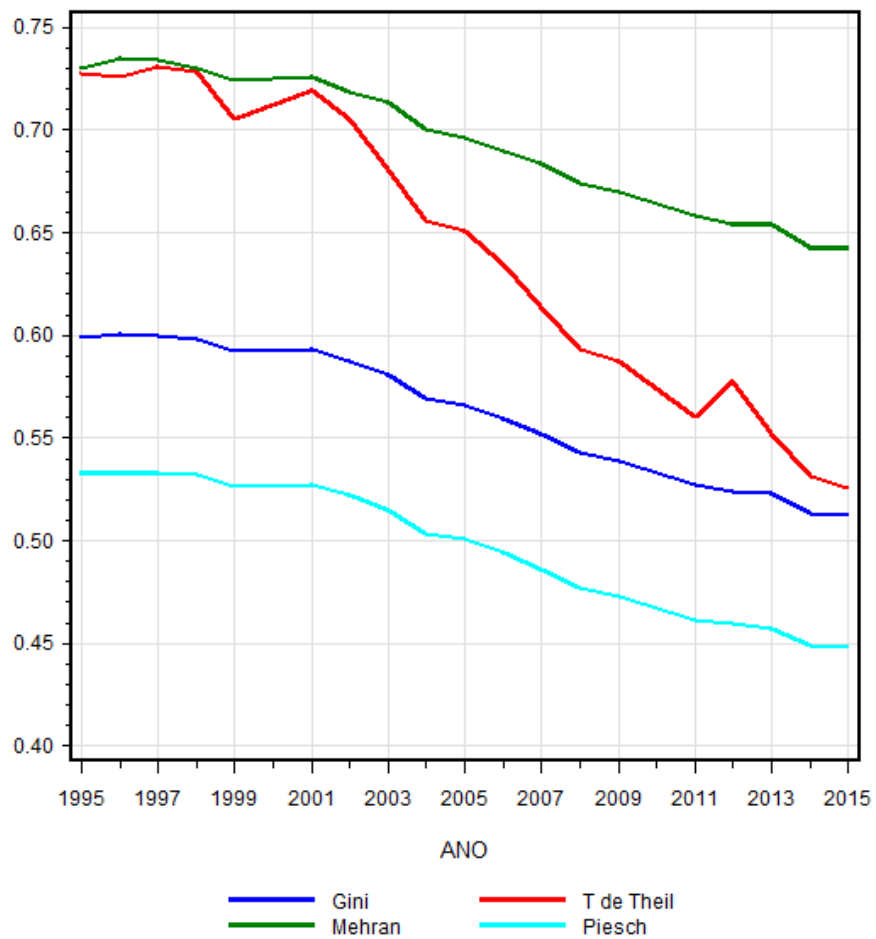

Figura 14

Participação de parcelas $\left(\varphi_{h}\right)$ no total da RDPC, no Brasil, de 1995 a 2015

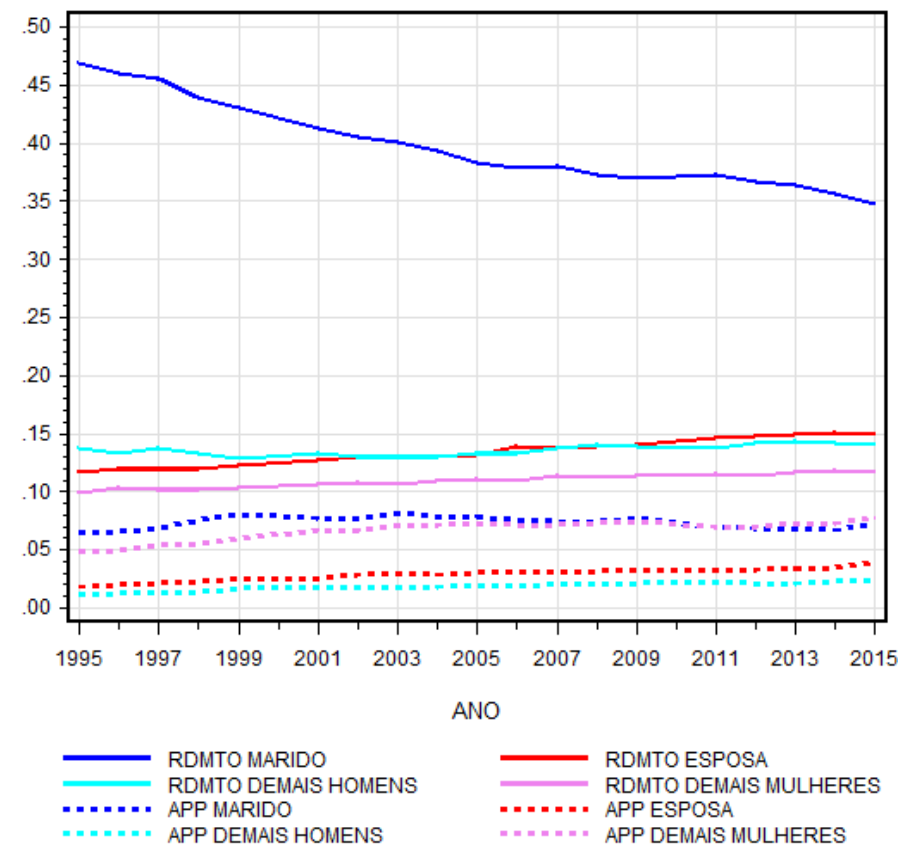


A evolução do índice de Gini da distribuição de cada parcela pode ser vista na Figura 15. É importante lembrar que esse índice leva em consideração os valores nulos da parcela, isto é, as pessoas dos domicílios nos quais essa parcela não existe. A redução do índice de Gini do rendimento de esposa se deve, essencialmente, à redução da porcentagem de pessoas que estão em domicílios nos quais a esposa não participa do mercado de trabalho, que passa de $71,4 \%$ em 1995 para 66,6\% em 2015.

Figura 15

Índice de Gini $\left(G_{h}\right)$ da distribuição de parcelas da RDPC, no Brasil, de 1995 a 2015



A associação entre cada parcela $\left(x_{h i}\right)$ e a posição de ordem $(i)$ da pessoa na distribuição da RDPC $\left(x_{i}\right)$ é captada pela correlação de Gini, cuja evolução pode ser vista na Figura 16. Para algumas parcelas se observa crescimento nos primeiros anos do período analisado, mas para todas as 8 parcelas, a correlação de Gini em 2015 fica substancialmente abaixo do seu valor em 1995. Examinando especificamente a correlação de Gini do rendimento do trabalho de esposas com a RDPC, verifica-se que ela mostra tendência decrescente no período, diminuindo de 0,741 em 1995 para 0,691 em 2015, mostrando que houve tendência de redução da associação entre o rendimento per capita do trabalho de esposas e a posição de ordem da respectiva RDPC. A evolução dessa correlação afeta diretamente a evolução do índice de Gini da RDPC, como mostra a expressão (11). Embora essa correlação esteja apenas indiretamente associada com a correlação entre escolaridades de maridos e esposas, pode-se dizer que o resultado observado na Figura 16 é coerente com a evolução da correlação entre as escolaridades mostrada na Figura 7. 
Figura 16

Correlação de Gini $\left(R_{h}\right)$ de parcelas com a RDPC, no Brasil, de 1995 a 2015

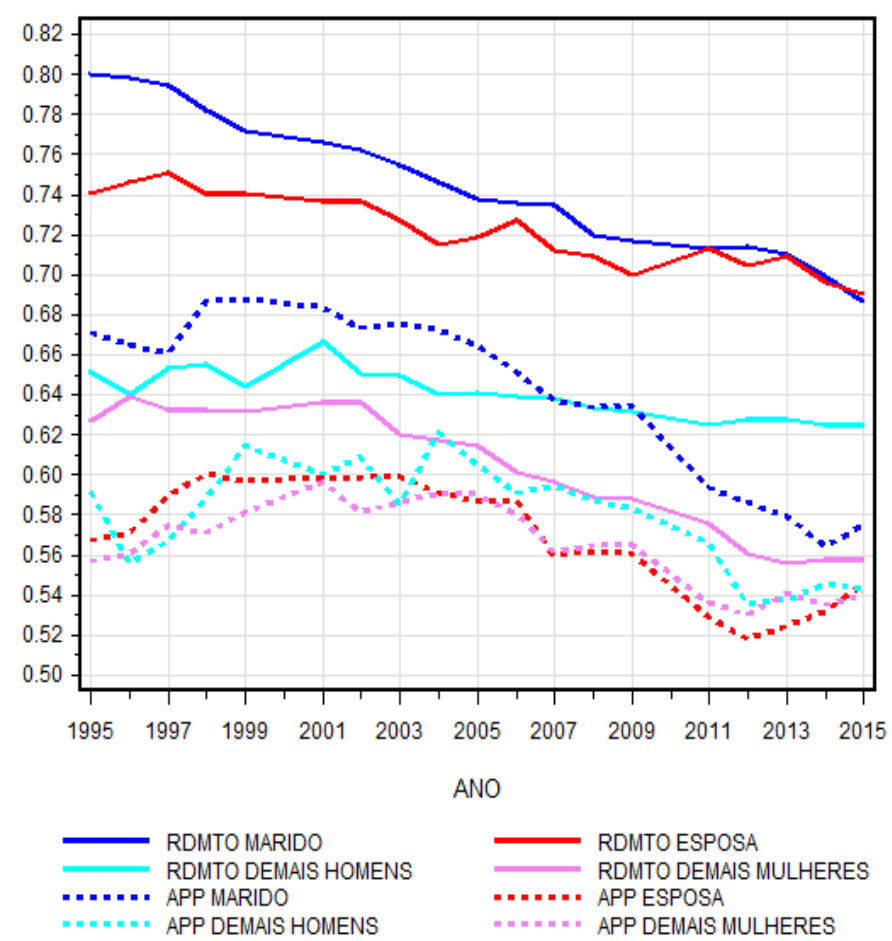

A Figura 17 mostra a variação da razão de concentração de cada uma das 8 parcelas, juntamente com a evolução do índice de Gini da RDPC. Quando a razão de concentração de uma parcela é maior do que o índice de Gini, dizemos que essa parcela é regressiva, pois, de acordo com a expressão (5), ela contribui para aumentar a desigualdade (medida pelo índice de Gini). O rendimento de esposa e aposentadorias e pensões (APP) de marido são as duas únicas, entre as 8 parcelas consideradas na Figura 17, que são regressivas durante todo o período analisado ${ }^{9}$. Como a razão de concentração é, por definição, o produto do índice de Gini da parcela pela respectiva correlação de Gini, as ordenadas das linhas da Figura 17 são o produto das ordenadas correspondentes nos Figuras 14 e 15. Como resultado de linhas estáveis ou decrescentes na Figura 15 e linhas predominantemente decrescentes na Figura 16, resultam linhas predominantemente decrescentes na Figura 17. Para as 8 parcelas, a razão de concentração em 2015 é menor do que seu valor em 1995.

A Figura 18 mostra como variou, de 1995 a 2015, o valor de cada parcela $\varphi_{h} C_{h}(h=1$, ..., 8) como porcentagem do índice de Gini da distribuição da RDPC em cada ano. Dada a dispersão relativamente pequena das razões de concentração dessas 8 parcelas, a Figura 18 mostra grande semelhança com a Figura 14, ou seja, a variação de cada parcela do índice de Gini reflete, essencialmente, a participação da parcela na renda domiciliar.

(9) A natureza regressiva de aposentadorias e pensões se deve à forte regressividade das aposentadorias e pensões de funcionários públicos, como mostra Hoffmann (2010). No Apêndice B é realizada uma análise dos determinantes imediatos da regressividade do rendimento do trabalho das mulheres. 
Figura 17

Índice de Gini da distribuição da RDPC e razões de concentração de 8 parcelas, no Brasil, de 1995 a 2015

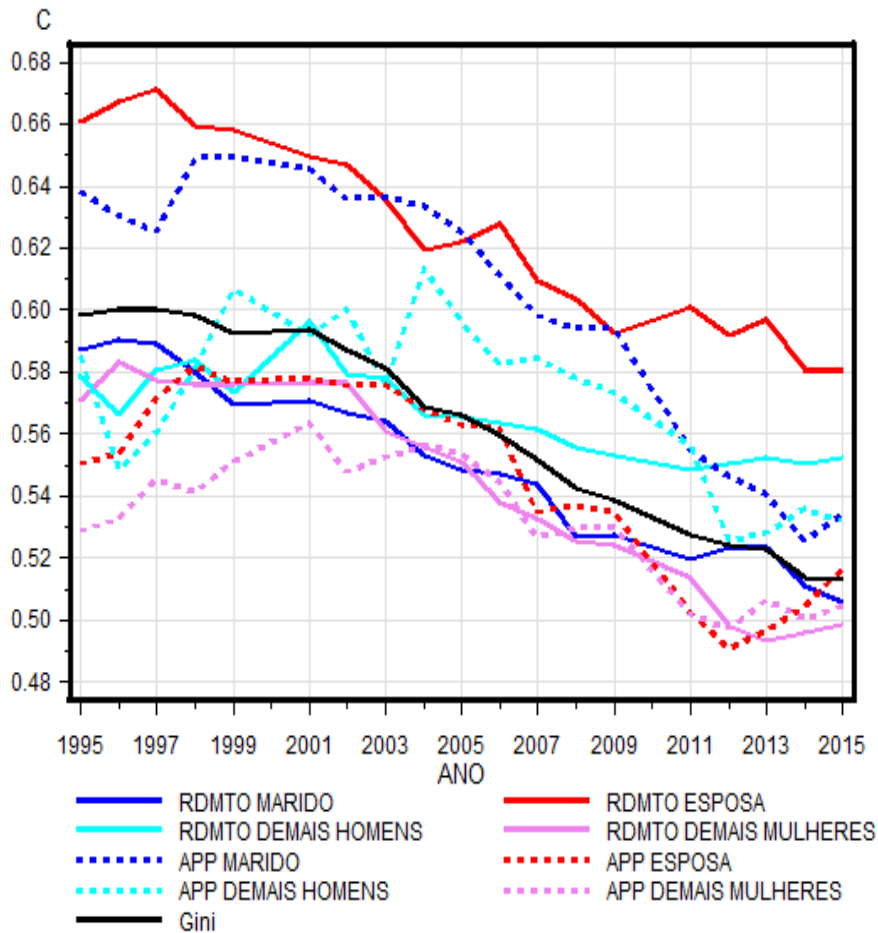

Figura 18

Participação de parcelas no índice de Gini da RDPC, no Brasil, de 1995 a 2015

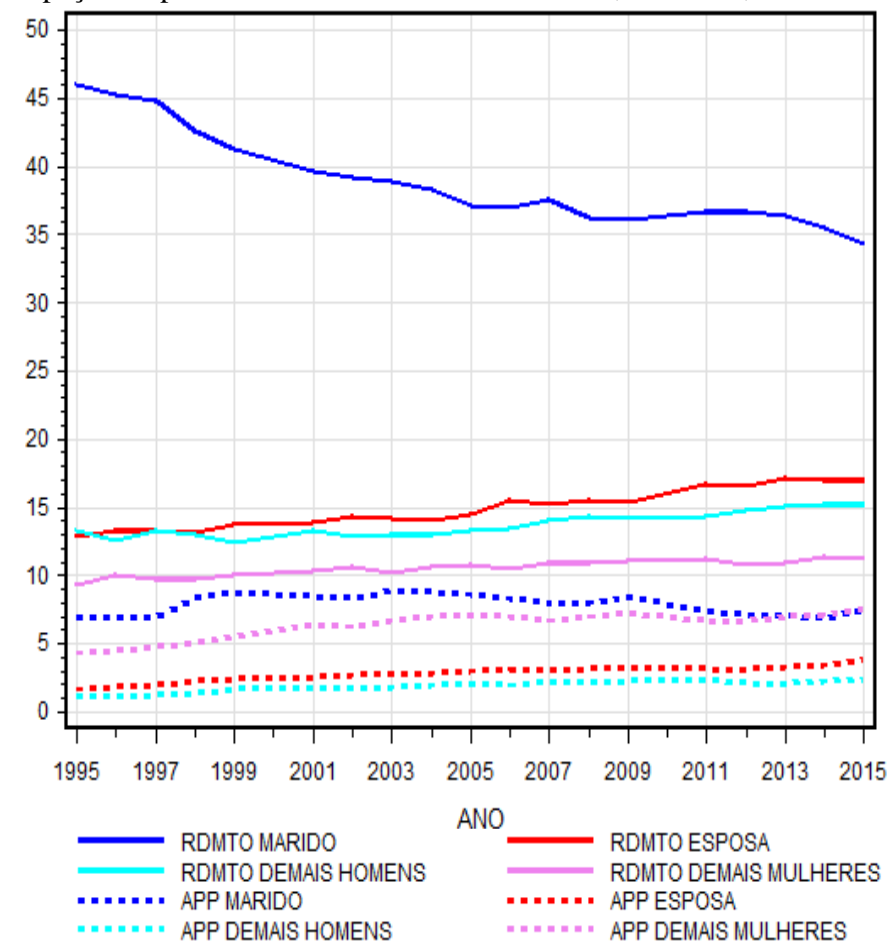


Com base na expressão (11) podemos avaliar a contribuição de cada parcela para a redução do índice de Gini de 1995 a $2015(\Delta G=-0,086)$. Os resultados estão na Tabela 1 , expressando os diversos efeitos de cada parcela como porcentagem de $\Delta G$. Notar que o efeito total é igual à soma dos efeitos composição e concentração, que, por sua vez, é igual à soma dos efeitos desigualdade e correlação.

Tabela 1

Participação porcentual de cada parcela e de cada efeito na redução do índice de Gini da distribuição da RDPC no Brasil de 1995 a $2015(\Delta G=-0,086)$

\begin{tabular}{|c|c|c|c|c|c|}
\hline Parcela & $\begin{array}{c}\text { Efeito } \\
\text { desigualdade }\end{array}$ & $\begin{array}{c}\text { Efeito } \\
\text { correlação }\end{array}$ & $\begin{array}{c}\text { Efeito } \\
\text { concentração }\end{array}$ & $\begin{array}{c}\text { Efeito } \\
\text { composição }\end{array}$ & Total \\
\hline $\begin{array}{l}\text { Rendimento de } \\
\qquad \begin{array}{l}\text { - Marido } \\
2 \text { - Esposa } \\
3 \text { - Demais homens } \\
\text { 4-Demais mulheres }\end{array}\end{array}$ & $\begin{array}{r}-1,23 \\
5,65 \\
0,38 \\
1,20 \\
\end{array}$ & $\begin{array}{r}39,95 \\
6,75 \\
3,80 \\
7,82 \\
\end{array}$ & $\begin{array}{r}38,72 \\
12,40 \\
4,18 \\
9,02 \\
\end{array}$ & $\begin{array}{r}-1,26 \\
-2,56 \\
-0,05 \\
0,44 \\
\end{array}$ & $\begin{array}{r}37,46 \\
9,84 \\
4,14 \\
9,46 \\
\end{array}$ \\
\hline $\begin{array}{l}\text { Aposentadorias e pensões } \\
\text { de } \\
\begin{array}{l}5 \text { - Marido } \\
6 \text { - Esposa } \\
7 \text { - Demais homens } \\
8 \text { - Demais mulheres }\end{array}\end{array}$ & $\begin{array}{l}1,13 \\
0,46 \\
0,09 \\
0,67 \\
\end{array}$ & $\begin{array}{l}7,19 \\
0,65 \\
0,99 \\
1,11 \\
\end{array}$ & $\begin{array}{l}8,32 \\
1,11 \\
1,08 \\
1,78 \\
\end{array}$ & $\begin{array}{r}-0,26 \\
0,51 \\
-0,04 \\
1,32 \\
\end{array}$ & $\begin{array}{l}8,06 \\
1,61 \\
1,04 \\
3,10 \\
\end{array}$ \\
\hline 9 - Doações & - & 0,88 & 0,88 & $-0,52$ & 0,36 \\
\hline 10 - Aluguéis & $-0,07$ & 1,28 & 1,21 & 3,13 & 4,34 \\
\hline 11 - Juros etc. & 0,50 & 16,47 & 16,97 & 3,62 & 20,59 \\
\hline Total & 8,78 & 86,90 & 95,68 & 4,32 & 100,00 \\
\hline
\end{tabular}

O maior efeito total é o de rendimento de marido, contribuindo com 37,5\% da redução do índice de Gini da distribuição da RDPC no período 1995 - 2015. Isso se deve, basicamente, à redução da correlação de Gini dessa parcela em relação à RDPC (ver Figura 16).

O segundo maior efeito total é o da parcela 11 (Juros, etc.), devido à grande expansão das transferências federais no período, que mudou totalmente o significado dessa parcela. Em 1995 ela correspondia a menos de $1 \%$ da renda total e sua razão de concentração era igual a 0,789 , pois era formada predominantemente de rendas concentradas nos relativamente ricos (juros e dividendos). Em 2015, a participação dessa parcela na renda total superou os $2 \%$ e sua razão de concentração se tornou negativa $(-0,197)$, pois ela passou a ser constituída predominantemente por transferências focalizadas nos pobres (com destaque para o Bolsa Família e o BPC).

A terceira maior contribuição para a redução da desigualdade está associada ao rendimento de esposas, corroborando a afirmativa de Ribeiro e Machado (2018, p. 232) de que "as mudanças na distribuição do rendimento do trabalho das mulheres em união conjugal contribuíram significativamente para a tendência de queda da desigualdade de renda entre 1992 e 2014" $"$ Note-se, na Tabela 1, que o rendimento do trabalho de esposas é a única das 11

(10) Cabe ressaltar que a metodologia usada por Ribeiro e Machado foi muito diferente. Toda sua análise está baseada no coeficiente de variação, que é uma medida de desigualdade muito sensível a mudanças na cauda superior da distribuição, e não 
parcelas analisadas com efeito desigualdade relativamente elevado, o que é consistente com o fato de corresponder à linha com tendência decrescente mais forte na Figura 15.

Todas as 11 parcelas contribuíram para reduzir a desigualdade e o efeito concentração é sempre positivo e, quase sempre, maior do que o efeito composição. Note-se que a soma dos efeitos concentração dessas 11 parcelas corresponde a 95,7\% da redução total do índice de Gini $^{11}$.

É interessante notar que, estaticamente, conforme dados da PNAD de 2015, podemos dizer que o rendimento de esposas contribui para maior desigualdade, pois sua razão de concentração $(0,581)$ é maior do que o índice de Gini da $\operatorname{RDPC}(0,513)$, mas quando analisamos a redução da desigualdade de 1995 a 2015 verificamos que as mudanças no rendimento das esposas no período contribuíram substancialmente para essa redução.

Agregando rendimentos de esposas e de demais mulheres, verifica-se que sua participação na renda total em 2015 é 26,6\%, com razão de concentração igual a 0,545, maior do que o índice de Gini da RDPC $(0,513)$, caracterizando o caráter regressivo desse agregado ${ }^{12}$.

Para captar eventual mudança de comportamento dentro do período analisado, a decomposição nos efeitos concentração e composição foi feita separadamente para os subperíodos 1995-2004 e 2004-2015, como mostra a Tabela 2. Nos dois subperíodos os quatro tipos de rendimento de atividade contribuíram para a redução da desigualdade, basicamente devido ao efeito concentração. De 2004 a 2015 o efeito total do rendimento de esposa é superado pelos efeitos de rendimento de demais mulheres e de aposentadorias e pensões de marido. Os efeitos totais de aposentadorias e pensões são todos positivos de 2004 a 2015, mas negativos no subperíodo 1995-2004, significando que mudanças nas aposentadorias entre 1995 e 2004 contribuíram para frear a queda na desigualdade.

Tabela 2

Participação porcentual de cada parcela e de cada efeito na redução do índice de Gini da distribuição da RDPC no Brasil de 1995 a $2004(\Delta G=-0,030)$ e de 2004 a $2015(\Delta G=-0,056)$

\begin{tabular}{l|c|c|c|c|c|c}
\hline \multirow{2}{*}{ Parcela } & \multicolumn{3}{c|}{ Período 1995 - 2004 } & \multicolumn{3}{c}{ Período 2004 - 2015 } \\
\cline { 2 - 7 } & $\begin{array}{c}\text { Efeito } \\
\text { concentração }\end{array}$ & $\begin{array}{c}\text { Efeito } \\
\text { composição }\end{array}$ & Total & $\begin{array}{c}\text { Efeito } \\
\text { concentração }\end{array}$ & $\begin{array}{c}\text { Efeito } \\
\text { Composição }\end{array}$ & Total \\
\hline Rendimento de & & & & & & \\
1 - Marido & 49,60 & $-3,37$ & 46,22 & 31,20 & $-0,92$ & 30,28 \\
2- Esposa & 17,15 & $-2,54$ & 14,61 & 9,59 & $-2,14$ & 7,44 \\
3 - Demais homens & 5,48 & $-0,26$ & 5,22 & 3,29 & $-0,36$ & 2,94 \\
4- Demais mulheres & 5,18 & 0,78 & 5,96 & 11,55 & 0,16 & 11,71 \\
\hline
\end{tabular}

no índice de Gini, que é uma medida de desigualdade mais sensível a mudanças na parte da distribuição com maior densidade de frequência (Hoffmann, 1998, cap. 7).

(11) Esse resultado depende da divisão em parcelas utilizada. Para as 11 parcelas consideradas em Hoffmann (2017), a soma dos efeitos concentração representa $72,3 \%$ de $\Delta G=-0,086$.

(12) O caráter regressivo do rendimento das mulheres foi constatado e discutido em Hoffmann e Leone (2004). 
Tabela 2 - Continuação

\begin{tabular}{|c|c|c|c|c|c|c|}
\hline \multirow[b]{2}{*}{ Parcela } & \multicolumn{3}{|c|}{ Período 1995 - 2004} & \multicolumn{3}{|c|}{ Período 2004 - 2015} \\
\hline & $\begin{array}{c}\text { Efeito } \\
\text { concentração }\end{array}$ & $\begin{array}{c}\text { Efeito } \\
\text { composição }\end{array}$ & Total & $\begin{array}{c}\text { Efeito } \\
\text { concentração }\end{array}$ & $\begin{array}{c}\text { Efeito } \\
\text { Composição }\end{array}$ & Total \\
\hline $\begin{array}{l}\text { Aposentadorias e } \\
\text { pensões de }\end{array}$ & & & & & & \\
\hline 5 - Marido & 1,20 & $-2,50$ & $-1,30$ & 13,40 & 0,51 & 13,91 \\
\hline 6 - Esposa & $-1,38$ & 0,87 & $-0,51$ & 3,05 & $-0,02$ & 3,03 \\
\hline 7 -Demais homens & $-1,43$ & $-0,32$ & $-1,75$ & 2,98 & $-0,29$ & 2,69 \\
\hline 8 - Demais mulheres & $-5,44$ & 3,16 & $-2,29$ & 6,81 & 0,12 & 6,92 \\
\hline 9 - Doações & $-1,39$ & 0,81 & $-0,58$ & 2,19 & $-1,17$ & 1,02 \\
\hline 10 - Aluguéis & 1,77 & 3,73 & 5,50 & 0,91 & 2,73 & 3,64 \\
\hline 11 - Juros etc. & 26,26 & 2,65 & 28,91 & 11,58 & 4,82 & 16,40 \\
\hline Total & 97,00 & 3,00 & 100,00 & 96,55 & 3,45 & 100,00 \\
\hline
\end{tabular}

\section{Conclusão}

Os dados da PNAD, de 1995 a 2015, não indicam que tenha aumentado a correlação entre a escolaridade do marido e a da esposa. Pelo contrário, todas as medidas de associação calculadas são menores em 2015 do que em 1995, coerentemente com resultados anteriores de Silva (2003) e Ribeiro e Silva (2009). Se, para períodos mais longos, for verdade que essa correlação cresceu, isso não permite afirmar que os casamentos, no Brasil, estão ocorrendo cada vez mais entre pessoas de status socioeconômico semelhante, pois há um século os preconceitos então vigentes determinavam que as mulheres, em geral, não demandassem escolarização. Apenas mais recentemente é que se pode considerar que a escolaridade das mulheres reflete melhor seu status socioeconômico. Ao longo das décadas a escolaridade média das mulheres cresceu mais do que a dos homens e, no Brasil, a partir da década de 1990, as mulheres passaram a ter escolaridade superior à dos homens.

Durante todo o período 1995-2015 a razão de concentração do rendimento de esposas permaneceu substancialmente acima do índice de Gini, mostrando que essa parcela da RDPC é regressiva, isto é, contribui, em cada ano, para elevar a desigualdade da RDPC. Mas ao longo do período essa razão de concentração diminuiu, de maneira que o rendimento das esposas contribuiu para a redução da desigualdade da RDPC observada utilizando dados da PNAD. Verifica-se que esse efeito positivo do rendimento das esposas, contribuindo para reduzir a desigualdade, é resultado de um efeito composição negativo e um efeito concentração positivo e de maior valor absoluto. $\mathrm{O}$ efeito composição é negativo porque essa parcela é regressiva e sua participação na RDPC aumentou. O forte efeito concentração positivo resulta da soma de dois efeitos positivos: o efeito desigualdade (devido à redução do índice de Gini da distribuição do valor per capita do rendimento das esposas) e o efeito correlação (graças à redução da correlação de Gini do valor per capita do rendimento das esposas em relação à RDPC). 
Rodolfo Hoffmann

\section{Referências bibliográficas}

BARRO, R. J.; LEE, J. W. A new data set of educational attainment in the world, 1950-2010. Journal of Development Economics, 104, p. 184-198, 2013.

BELTRÃO, K. I.; ALVES, J. E. D. A reversão do hiato de gênero na educação brasileira no século XX. Caderno de Pesquisa, São Paulo, v. 39, n. 136, jan./abr. 2009.

EIKA, L.; MOGSTAD, M.; ZAFAR, B. Educational assortative mating and household income inequality. Federal Reserve Bank of New York, Revised March 2017. (Staff Reports).

FEI, J. C. H.; RANIS, G.; KUO, S. W. Y. Growth with equity: the Taiwan case. World Bank Research Publication, Oxford University Press, 1979.

GREENWOOD, J. et al. Marry your like: assortative mating and income inequality. American Economic Review Papers and Proceedings, v. 104, n. 5, p. 1-15, 2014.

GREENWOOD, J. et al. Technology and changing family: a united model of marriage, divorce, educational attainment, and married female labor-force participation. American Economic Journal: Macroeconomics, v. 8, n. 1, p. 1-41, 2016.

HAKAK, L.; FIRPO, S. Household income inequality and education in marriage Market in Brazil: an empirical study. Available at: https://www.fea.usp.br/sites/default/files/anexoevento/chapter2 article new version 3 15.pdf.

HOFFMANN, R. Distribuição de renda: medidas de desigualdade e pobreza. São Paulo: Editora da Universidade de São Paulo, 1998.

HOFFMANN, R. Desigualdade da renda e das despesas per capita no Brasil, em 2002-2003 e 2008-2009, e avaliação do grau de progressividade ou regressividade de parcelas da renda familiar. Economia e Sociedade, Campinas, v. 19, n. 3 (40), p. 647-661, dez. 2010.

HOFFMANN, R. Desigualdade da distribuição da renda no Brasil: o que mudou em 2015? Rio de Janeiro: IEPE/Casa das Garças, 2017. (Texto para Discussão, n. 38).

HOFFMANN, R. How to measure the progressivity of an income component. Applied Economics Letters, v. 20, p. 328-331, 2013.

HOFFMANN, R. Transferências de renda e a redução da desigualdade no Brasil e cinco regiões entre 1997 e 2004. Econômica, Rio de Janeiro, v. 8, n. 1, p. 55-81, jun. 2006.

HOFFMANN, R.; KAGEYAMA, A.A. Distribuição da renda o Brasil, entre famílias e entre pessoas, em 1970 e 1980. Estudos Econômicos, São Paulo, v. 16, n. 1, p. 25-51, jan./abr. 1986.

HOFFMANN, R.; LEONE, E. T. Participação da mulher no mercado de trabalho e desigualdade da renda domiciliar per capita no Brasil: 1981-2002. Nova Economia, Belo Horizonte, v. 14, n. 2, p. 35-58, maio/ago. 2004. 
HOFFMANN, R.; OLIVEIRA, R. B. The evolution of income distribution in Brazil in the agricultural and the non-agricultural sectors. World Journal of Agricultural Research, v. 2, n. 5, p. 192-204, 2014.

IBGE. Pesquisa Nacional por Amostra de Domicílios 2007. Rio de Janeiro: Instituto Brasileiro de Geografia e Estatística, 2008.

JESUS, J. G.; HOFFMANN, R. Desigualdade de renda no Brasil: a contribuição de parcelas do rendimento domiciliar per capita, destacando o setor agrícola. Revista de Economia Agrícola, São Paulo, v. 62, n. 1, p. 25-40, jan./jun. 2015.

LEONE, E. Renda familiar e trabalho da mulher na Região Metropolitana de São Paulo nos anos 80 e 90. In: ROCHA, M. I. B. (Coord.), Trabalho e gênero: mudanças, permanências e desafios. Abep, Nepo/Unicamp e Cedeplar/UFMG, Editora 34, 2000.

NERI, M. C. Sexo, casamento e economia. Rio de Janeiro: FGV/IBRE, Centro de Políticas Sociais, 2005. 37p.

PEREIRA, L.; SANTOS, C. Casamentos seletivos e desigualdade de renda no Brasil. Revista Brasileira de Economia, Rio de Janeiro, v. 71, n. 3, p. 361-377, jul./set. 2017.

PYATT, G.; CHEN, C. N.; FEI, J. The distribution of income by factor components. The Quarterly Journal of Economics, v. 95, n. 3, p. 451-473, Nov. 1980.

RIBEIRO, C. A. C.; SILVA, N.V. Cor, educação e casamento: tendências da seletividade marital no Brasil, 1960 a 2000. DADOS - Revista de Ciências Sociais, Rio de Janeiro, v. 52, n. 1, p. 7-51, 2009.

RIBEIRO, C. A. C.; MACHADO, W. Rendimento do trabalho das esposas e tendências da desigualdade de renda no Brasil: 1992 a 2014. DADOS - Revista de Ciências Sociais, Rio de Janeiro, v. 61, n. 1, p. 207-239, 2018.

SCHWARTZ, C. R.; MARE, R. D. Trends in educational assortative marriage from 1940 to 2003. Demography, v. 42, n. 4, Nov. 2005.

SILVA, N. V. Duas décadas de seletividade marital educacional no Brasil. In: HASENBALG, C.; SILVA, N. V. (Org.). Origens e destinos: desigualdades sociais ao longo da vida. Rio de Janeiro: Topbooks, 2003.

YITZHAKI, S.; SCHECHTMAN, E. The Gini Methodology: a primer on a statistical methodology. Springer Science \& Business Media, 2012. 


\section{Apêndice A}

\section{Exemplo numérico com parcela altamente desigual que pode contribuir para reduzir a desigualdade final}

1. A Tabela A1 mostra dados artificiais para uma população de 5 pessoas cuja renda $x$ é formada por duas parcelas $\left(x_{1}\right.$ e $\left.x_{2}\right)$. A posição de ordem da renda final é indicada por $i$. As posições de ordem das parcelas $x_{1}$ e $x_{2}$ são indicadas por $i_{1}$ e $i_{2}$, respectivamente. Verifica-se que os valores de $x_{1}$ seguem a mesma ordenação que os valores de $\mathrm{x}\left(i_{1}=\right.$ $i)$. Para facilitar o cálculo de covariâncias, colocamos nas últimas colunas os valores centrados das posições de ordem.

Tabela A1

Dados artificiais para rendas de 5 pessoas

\begin{tabular}{c|c|c|c|c|c|c|c|c}
\hline$I$ & $x$ & $x_{1}$ & $x_{2}$ & $i_{1}$ & $i_{2}$ & $i^{*}$ & $i_{1}^{*}$ & $i_{2}^{*}$ \\
\hline 1 & 1 & 1 & 0 & 1 & 1 & -2 & -2 & -2 \\
\hline 2 & 2 & 1 & 1 & 2 & 3 & -1 & -1 & 0 \\
\hline 3 & 4 & 2 & 2 & 3 & 4 & 0 & 0 & 1 \\
\hline 4 & 11 & 4 & 7 & 4 & 5 & 1 & 1 & 2 \\
\hline 5 & 22 & 22 & 0 & 5 & 2 & 2 & 2 & -1 \\
\hline
\end{tabular}

Para a renda final $x$ obtemos $\mu=8, \operatorname{cov}(i, x)=\frac{1}{5} \sum i^{*} x=\frac{51}{5}$ e $G=0,51$.

Para a parcela $x_{1}$ verifica-se que $\varphi_{1}=\frac{3}{4}, \mu_{1}=6, \operatorname{cov}\left(i_{1}, x_{1)}=9\right.$ e $G_{1}=0,6$.

Para a parcela $x_{2}$ obtemos $\varphi_{2}=\frac{1}{4}, \mu_{2}=2, \operatorname{cov}\left(i_{2}, x_{2}\right)=3,2$ e $G_{2}=0,64$.

Como a ordenação dos $x_{1}$ coincide com a ordenação dos $x, R_{1}=1$.

A correlação de Gini de $x_{2}$ em relação a $x$ é

$$
R_{2}=\frac{\operatorname{cov}\left(i, x_{2}\right)}{\operatorname{cov}\left(i_{2}, x_{2}\right)}=\frac{1,2}{3,2}=\frac{3}{8}
$$

Pode-se verificar a validade da expressão (9):

$$
\begin{gathered}
\varphi_{1} R_{1} G_{1}+\varphi_{2} R_{2} G_{2}=G \\
\frac{3}{4} \cdot 1 \cdot 0,6+\frac{1}{4} \cdot \frac{3}{8} \cdot 0,64=0,51
\end{gathered}
$$

Note-se que, apesar da elevada desigualdade da distribuição de $x_{2}$, com $G_{2}=0,64$, ela contribui para reduzir a desigualdade. 
A expressão (5) mostra que o índice de Gini é uma média ponderada das razões de concentração. Como $C_{2}=R_{2} G_{2}=0,24$, substancialmente menor do que $G=0,51$, a parcela $x_{2}$ é denominada progressiva, por contribuir para reduzir a desigualdade final.

Vamos admitir, agora, que a parcela $x_{2}$ seja reordenada, de maneira que suas posições de ordem sejam idênticas às de $x_{1}$. Isso altera os valores finais $x$, como mostra a Tabela A2.

Tabela A2

Reordenando $x_{2}$, tornando-a uma parcela regressiva

\begin{tabular}{l|r|r|r|r|r|r|r|r}
\hline$I$ & $x$ & $x_{1}$ & $x_{2}$ & $i_{1}$ & $i_{2}$ & $i^{*}$ & $i_{1}^{*}$ & $i_{2}^{*}$ \\
\hline 1 & 1 & 1 & 0 & 1 & 1 & -2 & -2 & -2 \\
\hline 2 & 1 & 1 & 0 & 2 & 2 & -1 & -1 & -1 \\
\hline 3 & 3 & 2 & 1 & 3 & 3 & 0 & 0 & 0 \\
\hline 4 & 6 & 4 & 2 & 4 & 4 & 1 & 1 & 1 \\
\hline 5 & 29 & 22 & 7 & 5 & 5 & 2 & 2 & 2 \\
\hline
\end{tabular}

Para os novos valores de $x$ a média continua sendo $\mu=8$, mas a desigualdade fica maior, podendo-se verificar que $\operatorname{cov}(i, x)=\frac{1}{5} \sum i^{*} n=\frac{61}{5}$ e $G=0,61$.

Como os valores de $x_{2}$ continuam os mesmos, não há alteração na sua média e no seu índice de Gini. Mas modifica-se sua covariância com a posição de ordem da renda final $x$, sua correlação de Gini em relação a $x$ passa a ser

$$
R_{2}=\frac{\operatorname{cov}\left(i, x_{2}\right)}{\operatorname{cov}\left(i_{2}, x_{2}\right)}=\frac{3,2}{3,2}=1
$$

e sua razão de concentração aumenta para $C_{2}=0,64$.

Após essa reordenação de $x_{2}$, os valores correspondentes à equação

$$
\varphi_{1} R_{1} G_{1}+\varphi_{2} R_{2} G_{2}=G
$$

passam a ser

$$
\frac{3}{4} \cdot 1 \cdot 0,6+\frac{1}{4} \cdot 1 \cdot 0,64=0,61
$$

Verifica-se que agora $x_{2}$ é uma parcela regressiva, contribuindo para aumentar a desigualdade final. 


\section{Apêndice B}

\section{A distribuição dos domicílios, das pessoas e da renda conforme estratos de RDPC em 2015}

A Tabela 2 de Hoffmann e Leone (2004, p. 44) mostra várias características da distribuição das pessoas e da renda em 15 estratos de RDPC, no Brasil, em 2002. As Tabelas B1 e B2 deste Apêndice apresentam análise semelhante para 2015, considerando 9 estratos de RDPC.

A porcentagem de domicílios com rendimento de trabalho de mulher cresce de $46,9 \%$ em 2002 para 47,7\% em 2015. A participação do rendimento do trabalho de mulheres na renda total cresce mais: de $23,8 \%$ em 2002 para $26,6 \%$ em 2015. Também cresceu bastante a porcentagem de mulheres entre pessoas com rendimento do trabalho: de 38,6\% para $41,9 \%$.

Observa-se que tanto em 2002 como em 2015 essas porcentagens são mais baixas nos estratos mais pobres, se elevam em estratos intermediários e diminuem um pouco nos estratos mais ricos. Conforme já assinalado por Leone (2000), a maior participação da mulher na atividade econômica ocorre entre mulheres pertencentes a camadas não pobres. "A menor participação das mulheres dos estratos inferiores de renda deve-se, provavelmente, às dificuldades dessas mulheres de sair do lar para o trabalho remunerado por causa do cuidado dos filhos, associadas à falta de creches no País" (Hoffmann e Leone, 2004, p. 45).

Tabela B1

Distribuição dos domicílios, das pessoas e da renda total em 9 estratos de RDPC e porcentagem, em cada estrato, de domicílios com mulheres com rendimento do trabalho e porcentagem dessas mulheres no total de pessoas com rendimento do trabalho. Brasil $^{(1)}, 2015$.

\begin{tabular}{l|r|r|r|c|c}
\hline Estrato de RDPC & $\begin{array}{c}\text { \% de } \\
\text { domicílio } \\
\text { s }\end{array}$ & \% de pessoas & $\begin{array}{c}\% \text { da renda } \\
\text { total }\end{array}$ & $\begin{array}{c}\text { \% de domicílios com } \\
\text { mulher com rdmto do } \\
\text { trabalho }\end{array}$ & $\begin{array}{c}\text { \% de mulheres entre } \\
\text { pessoas com rdmto } \\
\text { do trabalho }\end{array}$ \\
\hline RDPC nula & 0,6 & 0,4 & 0 & 0 & - \\
\hline Mais de 0 a 300 & 13,8 & 18,6 & 3,3 & 29,3 & 34,5 \\
\hline Mais de 300 a 600 & 22,3 & 26,1 & 11,0 & 45,4 & 39,7 \\
\hline Mais de 600 a 900 & 21,9 & 19,8 & 14,0 & 45,1 & 42,8 \\
\hline Mais de 900 a 1.200 & 12,2 & 11,3 & 11,1 & 57,9 & 43,4 \\
\hline Mais de 1.200 a 2.000 & 15,7 & 13,3 & 19,2 & 55,9 & 45,4 \\
\hline Mais de 2.000 a 4.000 & 8,9 & 7,2 & 18,9 & 59,2 & 44,9 \\
\hline Mais de 4.000 a 7.000 & 2,9 & 2,2 & 10,6 & 57,0 & 43,5 \\
\hline Mais de 7.000 & 1,7 & 1,1 & 11,9 & 52,4 & 41,9 \\
\hline Total & 100,00 & 100,00 & 100,00 & 47,7 & \\
\hline
\end{tabular}

(1) Exclusive área rural da antiga região Norte.

O fato de a participação da renda do trabalho das mulheres ser menor nos estratos relativamente pobres implica na regressividade dessa parcela da RDPC. É o rendimento do trabalho de esposas que determina essa regressividade, pois o rendimento do trabalho das demais mulheres é progressivo (sua razão de concentração é menor do que o índice de Gini da 
distribuição da RDPC, como mostra a Figura 17). A Figura B1 ilustra a regressividade do rendimento do trabalho das esposas em 2015, mostrando como a participação desse rendimento na renda domiciliar tende a crescer do décimo mais pobre para o décimo mais rico ${ }^{13}$.

Tabela B2

Participação do rendimento do trabalho de homens e mulheres na renda, conforme estratos de RDPC, no Brasil ${ }^{(1)}$, em 2015

\begin{tabular}{l|c|c|c|c|c}
\hline \multirow{2}{*}{ Estratos de RDPC } & \multicolumn{2}{|c|}{$\%$ da renda total proveniente do rendimento do } & \multicolumn{2}{c}{$\begin{array}{c}\text { Razão entre rendimentos } \\
\text { médios do trabalho }\end{array}$} \\
\cline { 2 - 6 } & homens & mulheres & esposas & $\begin{array}{c}\text { Mulher/ } \\
\text { homem }\end{array}$ & $\begin{array}{c}\text { Esposa/ } \\
\text { marido }\end{array}$ \\
\hline Mais de 0 a 300 & 48,4 & 18,9 & 7,9 & 0,74 & 0,65 \\
\hline Mais de 300 a 600 & 49,9 & 24,1 & 11,7 & 0,73 & 0,64 \\
\hline Mais de 600 a 900 & 44,6 & 24,7 & 13,0 & 0,74 & 0,64 \\
\hline Mais de 900 a 1.200 & 49,5 & 27,9 & 15,1 & 0,74 & 0,63 \\
\hline Mais de 1.200 a 2.000 & 49,4 & 27,7 & 16,2 & 0,73 & 0,63 \\
\hline Mais de 2.000 a 4.000 & 47,8 & 28,4 & 16,7 & 0,72 & 0,61 \\
\hline Mais de 4.000 a 7.000 & 50,0 & 27,7 & 16,9 & 0,68 & 0,58 \\
\hline Mais de 7.000 & 52,4 & 26,5 & 15,8 & 0,66 & 0,56 \\
\hline Total & 48,9 & 26,6 & 15,0 & 0,76 & 0,71 \\
\hline
\end{tabular}

(1) Exclusive área rural da antiga região Norte.

Figura B1

Participação do rendimento do trabalho de esposas no rendimento domiciliar em cada décimo da distribuição da RDPC, Brasil, 2015

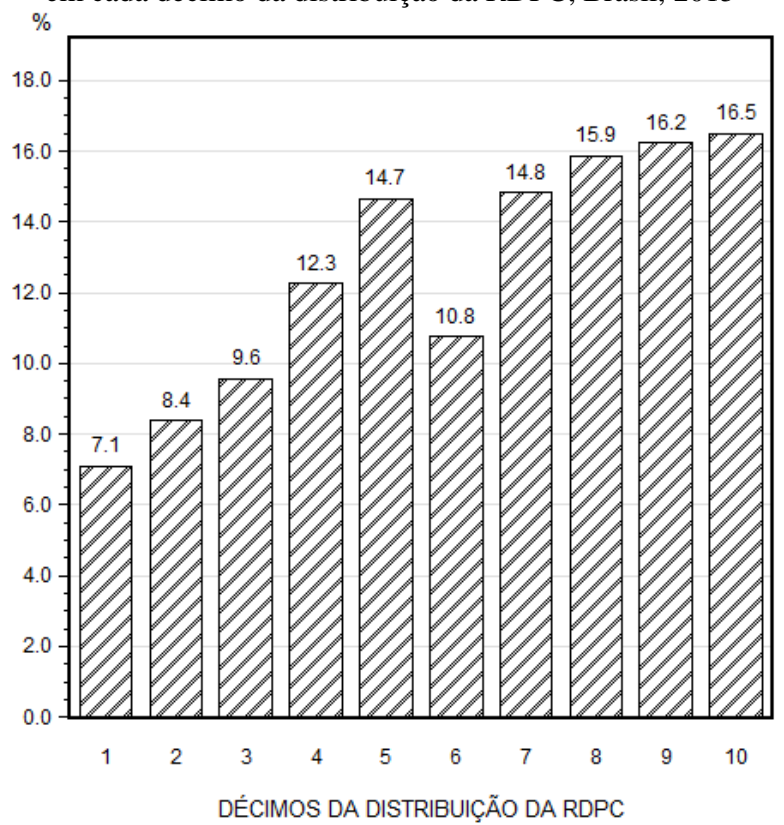

(13) A participação relativamente baixa no sexto décimo, na Figura B1, se deve ao fato de ele incluir rendas per capita iguais ao salário mínimo e, consequentemente, nesse décimo ser especialmente elevada a participação da renda de aposentadorias e pensões. 
Em 2002 o rendimento médio do trabalho de mulheres correspondia a $71 \%$ da respectiva média para homens. Em 2015 essa porcentagem subiu para 76\%, como mostra a Tabela B2. Observa-se que a razão entre medias de rendimentos do trabalho de mulheres e homens é mais alta nos estratos de RDPC mais baixa. A Tabela B2 mostra, também, que a razão entre rendimentos médios do trabalho é sempre mais baixa ao comparar esposas com maridos do que ao comparar, em geral, mulheres com homens. 